Portland State University

PDXScholar

\title{
Whole Body In Vitro Hydraulic Conductivity and Transcapillary Filtration in Two Amphibians, Bufo marinus and Rana catesbeiana
}

Thomas Vincent Hancock

Portland State University

Follow this and additional works at: https://pdxscholar.library.pdx.edu/open_access_etds

Part of the Biology Commons

Let us know how access to this document benefits you.

\section{Recommended Citation}

Hancock, Thomas Vincent, "Whole Body In Vitro Hydraulic Conductivity and Transcapillary Filtration in Two Amphibians, Bufo marinus and Rana catesbeiana" (1997). Dissertations and Theses. Paper 5744. https://doi.org/10.15760/etd.7615

This Thesis is brought to you for free and open access. It has been accepted for inclusion in Dissertations and Theses by an authorized administrator of PDXScholar. Please contact us if we can make this document more accessible: pdxscholar@pdx.edu. 


\section{THESIS APPROVAL}

The abstract and thesis of Thomas Vincent Hancock for the Master of Science in

Biology were presented on August 8, 1997, and accepted by the thesis committee and the department.

COMMITTEE APPROVALS:

Stanley S. Hiflman, Chair

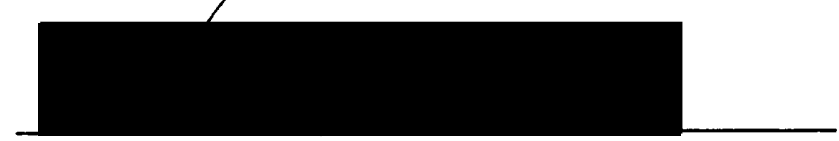

Richard B. Forbes

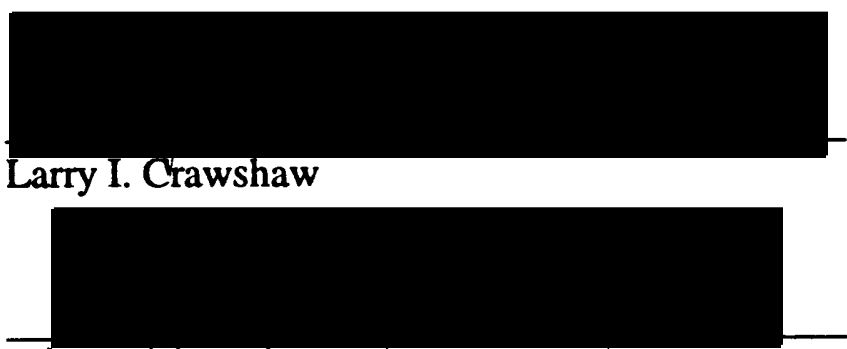

Gary R. Brodowicz

Representative of the Office of Graduate Studies

DEPARTMENT APPROVAL:

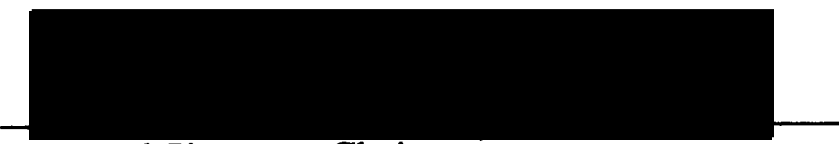

Leonard Simpson, Chair

Department of Biology

$* * * * * * * * * * * * * * * * * * * * * * * * * * * * * * * * * * * * * * * * * * * * * * * * * * * * * * * * * * * * * * * * * * *$

ACCEPTED FOR PORTLAND STATE UNIVERSITY BY THE LIBRARY

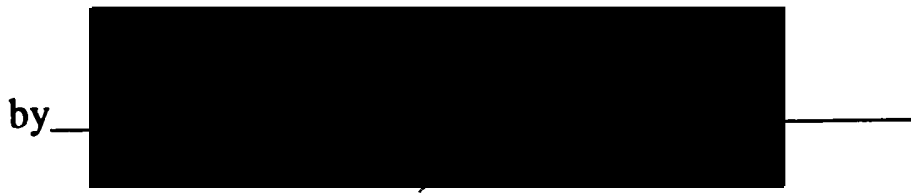
on

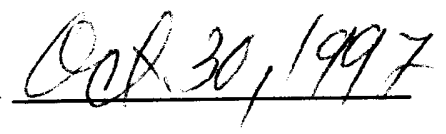




\begin{abstract}
An abstract of the thesis of Thomas Vincent Hancock for the Master of Science in Biology presented August 8, 1997.
\end{abstract}

Title: Whole Body In Vitro Hydraulic Conductivity and Transcapillary Filtration in Two Amphibians, Bufo marinus and Rana catesbeiana

The capillary filtration coefficient (CFC) and isovolumetric capillary pressure $\left(\mathrm{P}_{\mathrm{ci}}\right)$ were measured in Bufo marinus and Rana catesbeiana, using a gravimetric technique on an in vitro preparation while perfusing with Ringers and $0.1 \mathrm{~g} \cdot 100 \mathrm{ml}^{-1}$ bovine serum albumin Estimates of pre- and post-capillary resistance were obtained from Bufo; the post- to pre-capillary resistance ratio was found to be 0.18 , which was used to estimate capillary pressure. CFC was found to be $6.68 \pm 0.51$ and $5.07 \pm 0.23 \mathrm{ml} \cdot \mathrm{min}^{-1} \cdot \mathrm{kg}^{-1} \cdot \mathrm{mmHg}^{-1}$ and $\mathrm{P}_{\mathrm{ci}}$ was found to be 7.4 and $6.3 \mathrm{mmHg}$ in Bufo marinus and Rana catesbeiana, respectively. An in vivo estimate of isovolumetric capillary pressure, after correcting for osmotic pressures of plasma proteins, would be approximately 11.5 and $9.3 \mathrm{mmHg}$ for Bufo marinus and Rana catesbeiana, respectively. Using this resistance ratio, resting capillary pressures were estimated, based on published data, to be 10.8 and $11.3 \mathrm{mmHg}$ for Bufo marinus and Rana catesbeiana, respectively. These results show that both of these anuran amphibians have a very high CFC, indicating a highly permeable capillary membrane, but they do not begin to filter until very high hydrostatic pressures are reached. Further, the differences between Bufo marinus and Rana catesbeiana indicate that the reversal of Starling forces from net filtration to net 
absorption during hypovolemia would occur sooner in Bufo than in Rana. This is consistent with the superior dehydration tolerance seen in toads versus frogs. 
WHOLE BODY IN VITRO HYDRAULIC CONDUCTIVITY AND

TRANSCAPILLARY FILTRATION IN TWO AMPHIBIANS,

BUFO MARINUS AND RANA CATESBEIANA

by
THOMAS VINCENT HANCOCK

A thesis submitted in partial fulfillment of the requirements for the degree of

\section{MASTER OF SCIENCE \\ in \\ BIOLOGY}

Portland State Unniversity

1997 


\section{ACKNOWLEDGEMENTS}

I would like to thank all of those faculty and graduate students who contributed to this thesis and the atmosphere that made it possible. Most of all, I would like to thank Stan Hillman for his inspirational leadership in the laboratory and in life. Special thanks go to the other commitee members: Larry Crawshaw, Richard Forbes and Gary Brodowicz whose review of this thesis in the heart of summer was of invaluable assistance. Thanks to all of the other faculty members who I had the pleasure of teaching with or receiving instruction from, most especially Debbie Duffield, Randy Zelick, Leonard Simpson, David Hayteas and Bob Tinnin.

To the guys in the lab, my compadres who toiled side by side with me, I couldn't have done it without you and wouldn't have enjoyed it nearly as much. To an exceptional group of graduate students, past and present, who made life at Portland State highly rewarding. You know who you are. For the friends at Clark: Jim, Mark, Rick and John, thanks for all of your help and advice as well as a fun, valuable and rewarding experience.

Thanks to all of my friends and family outside of school, who provided invaluable outlets for life outside academia. Thank you Karmin for being my constant companion. Thanks Bob and Marty for being great friends.

Special thanks go to Andrew Welch, whose unique contributions always inspired me to "go to the next level". 


\section{TABLE OF CONTENTS}

ACKNOWLEDGEMENTS

ii

TABLE OF CONTENTS ............................................................................ ii

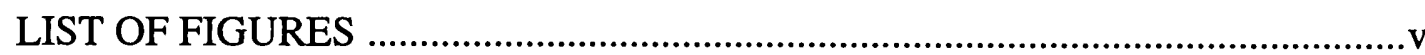

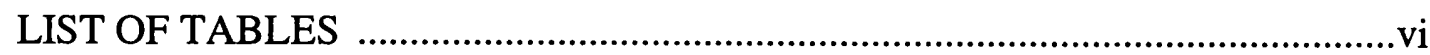

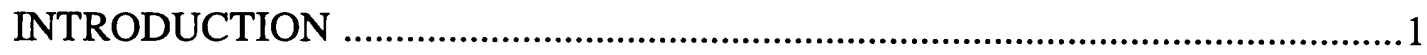

Transcapillary Filtration ......................................................................

Measurement of Hydraulic Conductivity ..................................................4

Variability of Hydraulic Conductivity......................................................5

Vascular and Interstitial Compliance ...................................................6

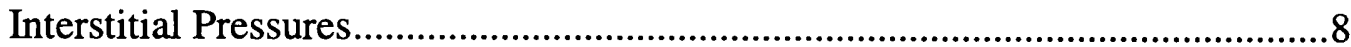

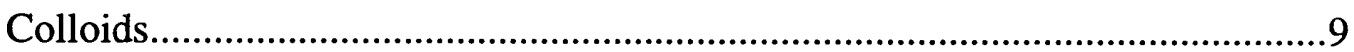

Reflection Coefficient and Protein Efflux ................................................ 11

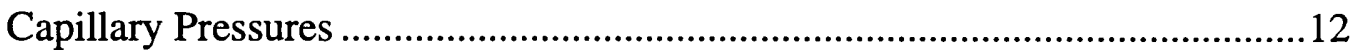

Mobilization of Interstitial Fluid ............................................................ 14

Hydraulic Conductivity and It's Measurement .......................................... 17

Capillary Filtration Coefficient and It's Measurement.................................18

Vertebrate Estimates of Hydraulic Conductivity.......................................19

Filtration in Specific Systems.......................................................... 21 
The Microvascular Membrane and the Inflammatory Response....................25

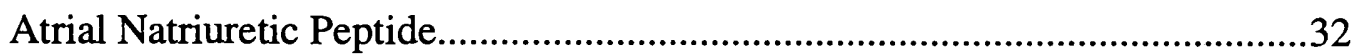

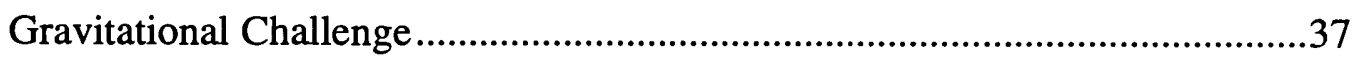

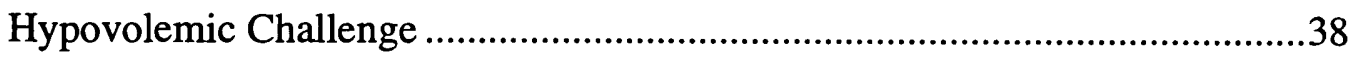

Statement of Purpose .........................................................................44

METHODS AND MATERIALS ..............................................................46

Hormonal Sensitivity of the System........................................................57

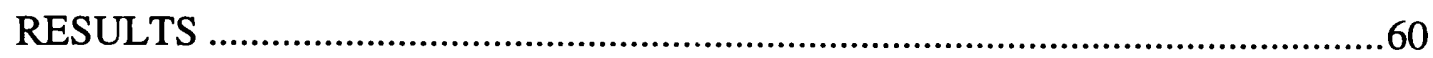

Isovolumetric Capillary Pressure and Pre- and Post-Capillary Resistance .......67

Histamine and Epinephrine ............................................................63

Capillary Filtration Coefficient ...........................................................64

Alternative Method of Calculating CFC and

Isovolumetric Capillary Pressure..............................................................67

Compliance vs. Mass ...................................................................... 70

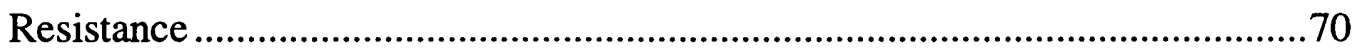

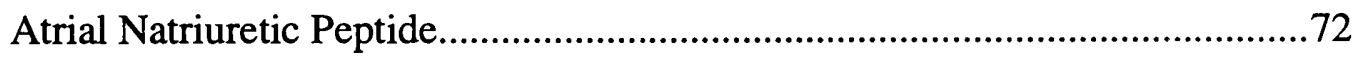

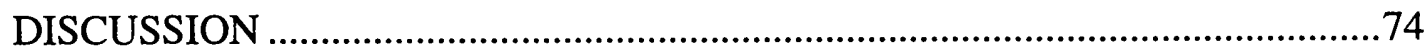

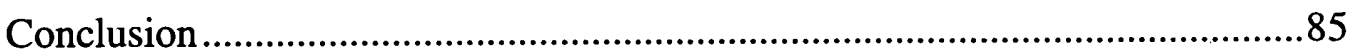

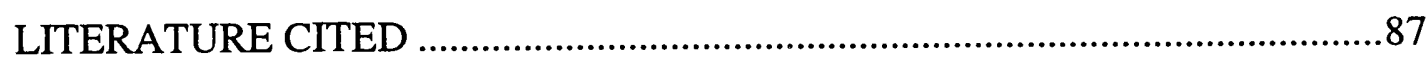




\section{LIST OF TABLES}

Table page

1. Isovolumetric Data Set and Pre- and Post-Capillary Resistances ..................62

2. Control measurements in Bufo marinus and Rana catesbeiana...................65

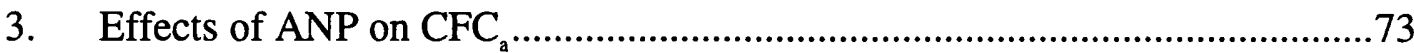




\section{LIST OF FIGURES}

Figure

1. Schematic Diagram of In Vitro preparation .47

2. Diagram of First Class Lever Device .51

3. Typical Traces of Arterial Pressure, Venous Pressure and Mass Changes .....54

4. Effect of Flow versus Isovolumetric Pressures ........................................61

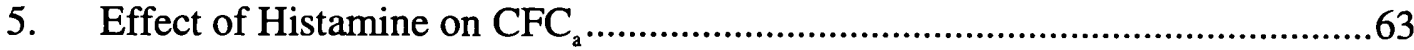

6. Interanimal and Interspecific Comparison of Control $\mathrm{CFC}_{\mathrm{a}} \ldots \ldots \ldots \ldots \ldots \ldots \ldots . . . . . .66$

7. Effect of Capillary Pressure on Filtration Rate .........................................68

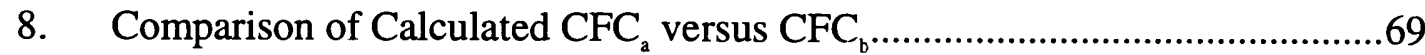

9. Correlation of Mass Versus Relative Compliance .....................................71 


\section{INTRODUCTION}

Maintenance of water distribution between the two primary compartments, intracellular and extracellular, and appropriate distribution of water between vascular and extravascular volume within the extracellular compartments are critical for normal physiological function in all organisms. The regulation of blood volume and blood pressure in vertebrates is vital to proper delivery of metabolites and removal of metabolic wastes. All are crucial to proper function of the organism as a whole.

Maintaining homeostasis of body water presents unique challenges for amphibians, a vertebrate class whose members are especially prone to dehydrational loss and consequently large fluctuations in body water (Shoemaker and Nagy, 1977). The high permeability of their skins and the large driving force of air result in high evaporative water loss. Conversely, the high permeability of the skin allows direct osmotic uptake of water. The advantages of this system include the ability to absorb oxygen and lose carbon dioxide through the skin. Amphibians occupy a wide spectrum of environmental niches and so require a variety of mechanisms to cope with these osmotic and volume stresses. A freshwater aquatic amphibian such as a frog tends to absorb water constantly from its surroundings due to the higher concentration of solutes in body tissues. Conversely, the terrestrial niche is a desiccating environment in which water is lost to evaporation, such that 
water is lost at a rate nearly equal to that of a free surface of water (Spotila and Berman, 1976), due to the high permeability of amphibian skin. Toads are much more terrestrial than frogs in general and have been shown to have higher tolerances to both hypovolemia and dehydration (Hillman et al., 1987; Hillman and Withers, 1988). Vertebrates, except for mammals, are known to possess lymphatic hearts, which are pulsatile organs capable of mobilizing fluid from the interstitium for return to the vasculature, thus enabling a high rate of return relative to that in mammals. Amphibians also have two additional sources of return, nephrostomal uptake and bladder water reabsorption. Nephrostomes return interstitial fluid from the peritoneum (Morris, 1981) while the bladder acts as a storage unit for the dilute urine which can be reabsorbed in times of stress.

\section{TRANSCAPILLARY FILTRATION}

Transcapillary filtration is a flow out of the capillaries into the interstitial fluid. It is primarily a result of a combination of forces, first characterized by Starling (1896). These are typically characterized as the hydrostatic pressures in the capillaries $\left(\mathrm{P}_{c}\right)$ being greater than hydrostatic pressures of the interstitium $\left(\mathrm{P}_{\mathrm{i}}\right)$, consequently pushing plasma through the walls of the capillaries. Return of fluid to the vasculature results from two primary avenues, colloid forces and lymphatic return. Colloid osmotic pressures (COP), also referred to as oncotic forces, are generated by proteins found in the capillary plasma $\left(\pi_{\mathrm{p}}\right)$ and the proteins found in 
the interstitial fluid or lymph $\left(\pi_{\mathrm{I}}\right)$. Normally, the higher colloid concentrations of the capillaries draw fluid back into the capillaries resulting in a flow opposite but not equal to that of hydrostatic flow, yielding a net flow outward. These variables were first envisioned by Starling (1896) and are represented by the modern form of Starling's fluid flux equation:

$$
J_{v}=L_{p} S\left(\left(P_{c}-P_{i}\right)-\sigma\left(\pi_{p}-\pi_{i}\right)\right)
$$

The variable $J_{v}$ represents flow or filtration where a positive $J_{v}$ indicates overall bulk fluid flow out of the capillary. The $S$ term is equivalent to surface area, which is directly related to the absolute fluid flux. Surface area can increase with the mobilization of new capillary beds or an increase in the diameter of individual capillaries. $\mathrm{L}_{\mathrm{p}}$ is the hydraulic conductivity and represents the permeability of the capillary wall and indicates how easily fluid can traverse the capillary wall where a $\mathrm{L}_{\mathrm{p}}$ of zero would indicate complete impermeability to fluid or extremely "tight" interendothelial cell junctions. A high $\mathrm{L}_{\mathrm{p}}$ would indicate extremely "leaky" endothelial cells. $P_{c}$ and $P_{i}$ represent the hydraulic pressures of the capillaries and interstitium, respectively. A higher capillary pressure would drive fluid out of the capillary, resulting in a higher $\mathrm{L}$. The variable $\sigma$ is the reflection coefficient which represents the permeability of the capillary wall to colloid proteins. This varies from zero to one, with a value of zero indicating complete permeability to colloid 
proteins and a value of one indicating no permeability. Thus, no permeability would maintain an extreme gradient of colloid pressures, resulting in a large reabsorption of fluid to the vasculature. A low reflection coefficient would allow proteins to leak out and increase $\pi_{\mathrm{i}} / \pi_{\mathrm{p}}$, the lymph to plasma ratio of plasma proteins, thus decreasing the osmotic gradient necessary for reabsorption. Normally, hydraulic pressures are higher than colloid forces, resulting in bulk flow out of the capillary.

\section{MEASUREMENT OF HYDRAULIC CONDUCTIVITY}

The hydraulic conductivity coefficient indicates how the filtration rate corresponds to the overall pressures, and consequently indicates how a change in these pressures will result in a change in the filtration rate. If the colloid osmotic pressures and interstitial hydrostatic pressures remain constant, and the hydrostatic pressure of the capillary is varied from $P_{1}$ to $P_{2}$, then the overall filtration rate will change from $F_{1}$ to $F_{2}$. By manipulation of the Starling equation (equation 1), the following formula for hydraulic conductivity can be derived.

$$
L_{p} S=I\left(F_{1}-F_{2}\right) /\left(P_{1}-P_{2}\right) I
$$

whether it is defined for a single capillary or capillary bed where surface area (S) is known, hydraulic conductivity $\left(\mathrm{L}_{\mathrm{p}}\right)$ can be derived. For a given mass of tissue, the capillary filtration coefficient $\left(\mathrm{CFC}=\mathrm{L}_{\mathrm{p}} \mathrm{S}\right)$ can be derived. 
Measurements of $\mathrm{L}_{\mathrm{p}}$ are made most often in two different manners.

Essentially, either can be termed a change in the rate of filtration for a given change in pressure. This pressure differential is absolutely expressed as a change in hydrostatic and colloid forces combined: $\left(P_{c}-P_{i}\right)-\sigma\left(\pi_{c}-\pi_{i}\right)$. Hydraulic conductivity (HC) is a term used for the direct measurement of $\mathrm{Lp}$, having units of $\mathrm{cm} \cdot \mathrm{min}^{-1} \cdot \mathrm{mmHg}^{-1}$ and is normally measured on single capillaries where the capillary area can be easily measured or on whole organs where the capillary surface area is estimated. Mass specific hydraulic conductivity, also called the capillary filtration coefficient (CFC) is most often measured in whole organs, limbs or for the whole body where an estimation of capillary surface area is foregone. It has units of $\mathrm{ml} \cdot \mathrm{min}^{-1} \cdot \mathrm{mmHg}^{-1} \cdot \mathrm{kg}$ tissue $\mathrm{e}^{-1}$. The first is expressed as the change in filtration rate per square centimeter of exchange surface, while the latter is expressed as the change in filtration rate per kilogram tissue. Both measurements can be calculated by inducing changes in the relative pressures of the capillary and the interstitium, whether it be induced by hydrostatic pressure changes or colloid osmotic changes, then measuring the resultant change in filtration rate.

\section{VARIABILITY OF HYDRAULIC CONDUCTIVITY}

All of these variables vary considerably between different capillaries, tissues, organs and organ systems depending on their particular function and location and even possibly between different seasons (Huxley and Curry, 1995; 
Zatsman and Thornhill, 1989 c.f. Glass et al., 1996). Morphological variation requires a flexibility in the properties of the microvascular membrane. For instance, capillaries in the giraffe foot are subject to extremely high pressures of $220 \mathrm{mmHg}$ (Hargens et al., 1987) due to the bloodstream acting as a continuous column of water equal to the difference in height from the heart to the foot. Since COP does not increase and $P_{c}$ is much higher, these capillaries must be extremely tight in order to avoid edema in the surrounding tissues. Other variables can also have the same effect. A high interstitial pressure would also tend to combat edema. Variability within a single capillary bed is extremely high and can have up to elevenfold differences along their length (Wiederhielm, 1966; Fraser et al., 1978).

\section{VASCULAR AND INTERSTITIAL COMPLIANCE}

The vascular compliance of the system, absolute changes in blood volume per change in pressure $\left(\mathrm{ml} \cdot \mathrm{mmHg}^{-1} \cdot \mathrm{kg}^{-1}\right)$ is a measure used to quantify the physical properties of the vasculature. If the blood pressure increases, the entire vascular system is stretched, due to the elastic walls of the blood vessels. The same concept applies to the interstitial space as a compartment.

Vascular compliance is important because it determines the ability of the circulation to respond to increases or decreases in blood pressure or blood volume. For instance, a high compliance system would have much smaller changes in blood pressure if the volume is suddenly increased than would a low compliance system. 
Similarly, sudden increases in blood pressure would result in a large distension of the vasculature (primarily the venous circuit) in a high compliance system while a low compliance system would yield much less distension of the vasculature. The compliance of the vasculature will especially affect the venous pressure with a concomitant effect on the capillary pressure, a primary component of the Starling equation.

Interstitial compliance is important because any appreciable filtration into the interstitium will result in edema if it is greater than lymphatic return. The buildup of fluids seen in edema will increase the hydrostatic pressure of the interstitium faster with a low compliance and thus limit future filtration as the interstitial pressure increases. A high compliance will allow filtration to continue longer. A low interstitial compliance can thus act as a restraint against edema formation.

In mammals, estimates of interstitial compliance range from 0.4 to 4.75 $\mathrm{ml} \cdot \mathrm{mmHg}^{-1} \cdot \mathrm{kg}^{-1}$. In the whole dog, it is $4.75 \mathrm{ml} \cdot \mathrm{mmHg}^{-1} \cdot \mathrm{kg}^{-1}$ (Tanaka, 1979). Cat skeletal muscle interstitial compliance was measured by Eliassen et al. (1974) as $1.4 \mathrm{ml} \cdot \mathrm{mmHg}^{-1} \cdot \mathrm{kg}^{-1}$ but was measured by Guyton at $0.4 \mathrm{ml} \cdot \mathrm{mmHg}^{-1} \cdot \mathrm{kg}^{-1}$ (c.f. Eliassen et al., 1974). Fetal values for sheep were exceptionally high: 45 $\mathrm{ml} \cdot \mathrm{mmHg}^{-1} \cdot \mathrm{kg}^{-1}$ (Brace and Gold, 1984).

In ectotherms, interstitial compliance has been measured in many snakes by Lillywhite (1993b) utilizing a microinjection technique. These figures vary from 
$400 \mathrm{ml} \cdot \mathrm{mmHg}^{-1}-1790 \mathrm{ml} \cdot \mathrm{mmHg}^{-1}$ in a transition from terrestrial/aquatic to arboreal snakes (Lillywhite, 1993b). This was a relative measure where the units are not equivalent for comparative data. Recently, a co-worker (Mikë Georgitsis, unpublished data) has measured interstitial compliance of the lymphatic sacs in the toad (Bufo marinus) at $520 \mathrm{ml} \cdot \mathrm{mmHg}^{-1} \cdot \mathrm{kg}^{-1}$ for the interfemoral lymphatic sac and $261 \mathrm{ml} \cdot \mathrm{mmHg}^{-1} \cdot \mathrm{kg}^{-1}$ for the interfemoral lymphatic sac.

Vascular compliance, measured in the whole dog is between 4.62 $\mathrm{ml} \cdot \mathrm{mmHg}^{-1} \cdot \mathrm{kg}^{-1}$ (Tanaka, 1979) and $6.3 \mathrm{ml} \cdot \mathrm{mmHg}^{-1} \cdot \mathrm{kg}^{-1}$ (Guyton et al., 1954). Vascular compliance of the sheep fetus was measured at $3.0 \mathrm{ml} \cdot \mathrm{mmHg}{ }^{-1} \cdot \mathrm{kg}^{-1}$ (Brace and Gold, 1984).

The vascular compliance of rainbow trout is $3.4 \mathrm{ml} \cdot \mathrm{mmHg}{ }^{-1} \cdot \mathrm{kg}^{-1}$ (Zhang et al., 1995). Recently, a co-worker (Todd Hoagland, unpublished data) has measured vascular compliance in the toad (Bufo marinus) and frog (Rana catesbeiana) at 3.7 and $2.2 \mathrm{ml} \cdot \mathrm{mmHg}^{-1} \cdot \mathrm{kg}^{-1}$, respectively.

\section{INTERSTITIAL PRESSURES}

The interstitial pressure is characteristically low, thus enabling the full hydrostatic pressure of the capillary to result in filtration. However, a high interstitial pressure can play a major part in offsetting these capillary hydrostatic forces, consequently decreasing filtration in tissues such as the heart. 
Guyton (1963 c.f. Eliassen et al., 1974) first proposed the concept of negative interstitial pressure using an implanted capsule technique. Eliassen et al. (1974) stated that there must be a near-zero or slightly positive pressure in the interstitial space of muscle due to the balance of forces studies, but not actually measuring interstitial compliance. A new method of estimating interstitial pressures by a wick method (see Prather et al., 1971 for a review) has generated estimates generally higher than those calculated by Guyton.

In ectotherms, Lillywhite (1993b) found slightly positive interstitial pressures of 0-3 mmHg in aquatic snakes. Hillman et al. (1987) found interstitial tissue pressures of approximately $-1 \mathrm{mmHg}$ in anurans (Rana catesbeiana and Bufo marinus).

\section{COLLOIDS}

Colloid differentials are much higher in mammals than in lower vertebrates, establishing a return of fluids nearly equal to those resulting from hydrostatic pressures and resulting in low overall outward filtration. Birds also have high colloid forces, but their exceptionally high hydrostatic pressures yield higher overall outward filtration rates proportionally greater than those found in mammals.

The interstitial protein concentration of lymph itself is often measured and considered the equivalent of interstitial fluids, as has been demonstrated by Garlick and Renkin (1970), although lymphatic nodules may alter the composition. 
Estimates of COP varies widely within vertebrates and within mammals from $18-24 \mathrm{mmHg}$. The COP of cat muscle is between $18-20 \mathrm{mmHg}$. This is due to a muscle lymph with $40-50 \%$ of the protein of plasma (Jacobsson and Kjellmer, 1964; Zweifach and Integlietta, 1971; Eliassen et al., 1974). The colloid plasma osmotic force in the interstitial fluid of the rat is well above one-third that in plasma (Aukland and Fadnes, 1973) so the resulting COP would probably be well below that of the cat. In man, the plasma colloid pressure is 23-24 $\mathrm{mmHg}$ (Zweifach and Integlietta, 1971). In a cat hindlimb preparation it was found that plasma colloid pressure exceeded capillary pressure by $1-2 \mathrm{mmHg}$ (Pappenheimer and Soto-Rivera, 1948).

The plasma oncotic pressure of lower vertebrates is substantially lower than that of mammals. Amphibians have generally been shown to have a COP of between 2 to $3 \mathrm{mmHg}$. Baldwin et al. (1993) found in Rana pipiens lymph and plasma protein concentrations of 1.4 and 2.4 grams per liter, respectively, resulting in a COP of $2.7 \mathrm{mmHg}$. Pinder and Smits (1993) found a ratio of lymph to plasma proteins in Rana catesbeiana of 0.67. Hillman et al. (1987), found a similar ratio of 0.61 in Rana catesbeiana, but a much lower ratio of 0.33 in Bufo marinus resulting in a higher $\mathrm{COP}$ of approximately $4-5 \mathrm{mmHg}$.

In a study of fishes, Hargens et al. (1974) found concentration in cod (Gadus morhua) and flounder (Pleuronectes platessa) a protein concentration in extravascular fluid almost equal to plasma protein. Thus, the mammalian paradigm 
of a COP slightly less than the hydrostatic gradient did not hold true. These fishes show an adaption to cold polar waters in which the plasma oncotic pressure varied from 8 to $202 \mathrm{mmHg}$ in temperate versus winter acclimated cod with corresponding interstitial oncotic pressures. Similarly, the Antarctic ice fishes (Chaenocephalus aceratus and Pseudochaenichthys georgianus) have similar ranges from 3 to 68 mmHg accompanied by dorsal aortic blood pressure between 8 to $15 \mathrm{mmHg}$. This pattern suggests high capillary permeability to proteins producing a low, nearly zero, effective colloid osmotic pressure not predicted by plasma protein concentration alone. This flexibility in plasma protein concentration enables the fish to change the levels of plasma and interstitial proteins as an anti-freezing device, without having to change hydrostatic pressure.

Fishes in general have low arterial pressures and capillary blood pressures, and retention of proteins in plasma is significantly less than in other vertebrates (Johansen and Hanson, 1968), thus minimizing the absorptive component of filtration.

\section{REFLECTION COEFFICIENT AND PROTEIN EFFLUX}

Conklin (1930) first demonstrated that blood proteins moved to lymph via filtration and that proteins are differentially filtered in the frog. In human muscle, water-soluble substances are transported through the microvascular membrane at differential rates with an ability inversely related to their molecular weight. The 
interendothelial gaps, with a width of 6-7 $\mathrm{nm}$ through which water crosses, are much larger than the water molecule, thus water crosses easily and is assigned a permeability of 1 . Other small molecules also cross relatively easily with relative permeabilities declining with increasing size (e.g. 0.96 for $\mathrm{NaCl}, 0.8$ for urea, 0.6 for glucose), until a prohibitive size is reached. These larger molecules such as albumin are highly impermeable and albumin has a relative permeability of 0.001 (Guyton and Hall, 1996). Thus, the reflection coefficient is high, at least in mammals, due to this impermeability to plasma proteins.

In anurans, the reflection coefficient was assumed by Baldwin et al. (1993) to be 0.5 in frogs, but the membrane was found to be more permeable to albumin which has a reflection coefficient of 0.8 . This disparity is in disagreement with Curry et al. (1976) who found no correlation in frog mesenteric capillaries between molecular size and the reflection coefficient of each.

Fish have low to near zero reflection coefficients. This permeability to protein is especially pronounced in cold-water species (Hargens et al., 1974), whereas more temperate species have relatively less permeable microvascular membranes (Johansen and Hanson, 1968).

\section{CAPILLARY PRESSURES}

The isovolumetric (or isogravimetric) capillary pressure is the pressure at which there is no net filtration into or out of the capillary. This does not imply that 
there is no exchange of fluid across the vessel, but simply that there is no net filtration over the entire range of vasculatures. Net filtration will occur at the arterial end, while net absorption will occur at the venous end of the capillary bed in the normal mammalian in vivo situation. As noted by Eliassen et al. (1974), it is not exactly the pressure of the midpoint of the capillary bed, but the "isovolumetric pressure of the exchange vessels" whose value would be biased toward the venular end of the capillary bed.

Average isovolumetric capillary pressures for mammals range between 8-17 $\mathrm{mmHg}$ (Smits and Ilowite, 1989). In the cat hindquarter it varies from 13-14 mmHg (Eliassen et al., 1974; Diana and Kaiser, 1970) to $15 \mathrm{mmHg}$. In man, it is around 18-19 due to the higher plasma colloid pressure (Zweifach and Integlietta, 1971). Actual capillary pressures in normal conditions are reviewed by Michel (1984), and it is obvious that actual capillary pressures in mammals are much higher, especially at the arteriolar end.

In an abstract by Smits and Ilowite (1989), capillary pressure of the isolated toad hindlimb was estimated to be $2.15 \mathrm{mmHg}$. This value is very low in comparison to mammalian values and implies that amphibian capillaries are still filtering at pressures well below those in mammals.

Normal capillary pressure is usually well above those found in an isovolumetric state, typically resulting in filtration. Average capillary pressure in the frog, as reviewed by Michel (1984), was from 9.5-15.0 mmHg. These values are 
higher than the values for typical venous pressures in frogs, measured at 8.0 in Rana catesbeiana (Hillman et al., 1987). Of course, this higher capillary pressure is normal as blood flows in an arterial to venous direction.

Mean circulatory filling pressure (MCFP) is the average pressure of the circulatory system as defined by the compliance of the system, such that if the heart was stopped and blood was equilibrated throughout the vasculature instantaneously, the resultant pressure would be the MCFP. It is also described as the pivot point, the equilibrium point in the vasculature where the pressure is independent of cardiac activity, i.e. the pressure would not change if the heart was stopped. The small venules are the estimated pivot point (Rothe, 1993), wherein pressure is slightly below that of the capillary bed.

In mammals, MCFP has been measured at $7.6 \mathrm{mmHg}$ in the laboratory rat (Samar and Coleman, 1978) and at 6.3 in the domestic dog (Guyton et al., 1954). In ectotherms, the MCFP of trout is $4.8 \mathrm{mmHg}$ (Zhang et al., 1995). Recently, a co-worker (Todd Hoagland, unpublished data) measured MCFP in Bufo marinus and Rana catesbeiana at 8.6 and $9.5 \mathrm{mmHg}$, respectively.

\section{MOBILIZATION OF INTERSTITIAL FLUID}

Filtration of plasma into the interstitium is inevitable in all vertebrates under some conditions. If colloidal forces and lymphatic return are not sufficient to return fluid to the blood volume, edema will result and severe imbalances in body water 
homeostasis will eventually result in physiological stresses beyond the tolerance of the organism (Baustian, 1988; Baldwin et al., 1993). All vertebrates other than mammals have lymphatic hearts to aid in this return, while the mammalian system relies on skeletal muscle pressure and interstitial pressure, resulting in a lower rate of lymphatic return than in other vertebrates, but sufficient to match the low filtration rates seen in mammals. The lymphatic system is also responsible for returning to the vasculature any proteins leaking into the interstitium. This is vital for maintenance of the colloid gradient, whether large or small. This leakage of proteins is dependent upon the reflection coefficient, which varies depending upon the particular properties of the specific protein type. In mammalian systems, it has been demonstrated that this leakage is correlated in large part with the molecular weight of the protein, such that the larger proteins tend to remain confined to the capillary. The majority of plasma proteins determining the osmotic gradient are albumin (69,000 daltons), gamma-globulins (156,000 daltons) and fibrinogen (340,000 daltons). For a review of these properties, see Michel (1984). No correlation was found in single vessel studies of frog mesenteric capillaries between molecular size and the reflection coefficient of each (Curry et al., 1976).

Lymphatic return in mammals plays a relatively minor role for return of hydrostatic filtration in comparison to reabsorption. Jacobsson and Kjellmer (1964) measured a filtration rate of 2.0 to $4.0 \mathrm{ml} \cdot \mathrm{min}^{-1} \cdot \mathrm{kg}^{-1}$ in exercising cat muscle, 
compared to a lymphatic return of 0.13 to $0.2 \mathrm{ml} \cdot \mathrm{min}^{-1} \cdot \mathrm{kg}^{-1}$., with the balance returning to the vasculature via capillary reabsorptive forces.

Next to the lymphatic system of mammals, that of anurans has been best characterized in vertebrates perhaps owing to the accessibility of the lymph hearts and lymph sacs. Lymph flow rates in anurans have been estimated as high as 4.3 $\mathrm{ml} \cdot \mathrm{min}^{-1} \cdot \mathrm{kg}^{-1}$ at rest and $5.8 \mathrm{ml} \cdot \mathrm{min}^{-1} \cdot \mathrm{kg}^{-1}$ for active Rana pipiens (Baldwin et al., 1993) using an indirect method with an assumption of $0.0005 \mathrm{ml}$ per lymph heart. Jones et al. (1992) calculated a lymph rate of $0.185 \mathrm{ml} \cdot \mathrm{min}^{-1} \cdot \mathrm{kg}^{-1}$ in a hydrated, resting Bufo marinus. Baustian (1988) calculated a lymphatic return rate of 0.7 and $1.6 \mathrm{ml} \cdot \mathrm{min}^{-1} \cdot \mathrm{kg}^{-1}$ in Bufo marinus for before and after hemorrhage, respectively. Jones et al. (1997) measured the flow in a posterior lymph heart, and an assumption of equal flow from the paired posterior and anterior lymph hearts yields an estimate of $1.73 \mathrm{ml} \cdot \mathrm{min}^{-1} \cdot \mathrm{kg}^{-1}$ in Bufo marinus.

Nephrostomal uptake from the peritoneum is an alternative mechanism for the mobilization of extravascular fluid. In Bufo marinus some $600-800$ ciliated apertures reside on the peritoneal surface of each kidney (Morris, 1981). These have a maximum pumping rate of $0.0083 \mathrm{ml} \cdot \mathrm{min}^{-1}$ as a whole. Thus, this avenue is not considered significant for the return of fluid to the vasculature relative to the lymphatics. 


\section{HYDRAULIC CONDUCTIVITY AND ITS MEASUREMENT}

Single capillary methods of estimating hydraulic conductivity were first developed by Landis (1925). These methods have the advantage of being independent of the rate of flow, proportion of capillary beds being perfused and all of the general confounding factors related to mass specific CFC. They allow probing of the microvascular membrane independent of hemodynamic variables. Amphibian capillaries differ from mammalian capillaries. They are larger ( $20 \mu \mathrm{m}$ in diameter) due to the larger, nucleated erythrocytes of amphibians. This makes amphibian capillaries especially useful for single capillary methods, and consequently much of the work done at this level uses amphibian models (Oleson and Crone, 1984 c.f. Grega, 1986; Meyer and Huxley, 1990; Huxley and Meyer, 1990; Meyer et al., 1992).

An alternative method for measuring the permeability of the microvascular membrane is a measurement of its resistance. Current injected via a microelectrode within the capillary will spread predictably. Knowing the spread of current within the microvessel allows the ionic conductance of the vessel wall to be determined. This method is especially applicable to small ion conductance, a difficult factor to establish otherwise. This method has allowed further probing of the microvascular membrane (Crone and Christensen, 1981; Crone, 1986). Resistance is expressed in units of of $\Omega \cdot \mathrm{cm}^{2}$. Conductance, the inverse of resistance, is directly related to $\mathrm{HC}$, while resistance has an inverse relationship. 
Crone (1986) has established this method in cerebral postcapillary venules, measuring a change in this conductance due to several effectors including several autocoids, and has demonstrated that the effect is rapid, dose-dependent and fully reversible in a dose-dependent manner.

Mesenteric capillaries of the frog had an average of $1.85 \Omega \cdot \mathrm{cm}^{2}$ with a range of $3.0 \Omega \cdot \mathrm{cm}^{2}$ arteriolar to $0.95 \Omega \cdot \mathrm{cm}^{2}$ for mid- and venous capillaries (Crone, 1986). This estimate unfortunately lacks a variety of interspecific comparisons.

\section{CAPILLARY FILTRATION COEFFICIENT AND ITS MEASUREMENT}

At the organismal level, these different systems can be combined to give whole body transcapillary filtration (WBTF). This work was pioneered by Pappenheimer and Soto-Rivera (1948). WBTF is measured as the total amount of flow out of capillaries per minute per kilogram body mass $\left(\mathrm{ml} \cdot \mathrm{min}^{-1} \cdot \mathrm{kg}^{-1}\right)$ and is somewhere between the high and low CFCs of the system. CFC can also be measured within distinct tissue types or organs. This information adds significant knowledge about the relative importance of each system in contributing to whole body filtration as well as providing functional information about that particular system.

The filtration rate can also be estimated by measuring plasma volume over time. This can be accomplished by tagging erythrocytes (Tanaka, 1979; Morimoto 
et al., 1981) or measuring hematocrit. This requires continuous monitoring of the blood over time.

Volumetric methods rely on the measurement of the change in the overall mass of tissue, whether it be an organ, limb or whole animal. The mass change is presumed to be due to transcapillary exchange, and a subsequent increase (filtration) or decrease (reabsorption) can be measured over time to yield a filtration rate. This method has been used by many workers (Pappenheimer and Soto-Rivera, 1948; Diana and Kaiser, 1970; Rippe and Grega, 1978; Smits and Ilowite, 1989)

\section{VERTEBRATE ESTIMATES OF HYDRAULIC CONDUCTIVITY}

Estimates of normal CFC for mammals range from 0.4 to 0.74

$\mathrm{ml} \cdot \mathrm{min}^{-1} \cdot \mathrm{kg}^{-1} \cdot \mathrm{mmHg}^{-1}$ in isolated hindlimb preparations, which would most closely reflect the CFC of skeletal muscle. CFC was 0.4-0.5

$\mathrm{ml} \cdot \mathrm{min}^{-1} \cdot \mathrm{kg}^{-1} \cdot \mathrm{mmHg}^{-1}$ using volumetric techniques in the cat hindlimb (Eliassen et al., 1974) to $0.74 \mathrm{ml} \cdot \mathrm{min}^{-1} \cdot \mathrm{kg}^{-1} \cdot \mathrm{mmHg}^{-1}$ in the dog for whole body estimates using hematocrit methods to obtain vascular and interstitial compliance, then modeling the system to obtain CFC (Tanaka, 1979; Morimoto et al., 1981). In maximally dilated hindquarters of the rat, control CFC was 0.48 $\mathrm{ml} \cdot \mathrm{min}^{-1} \cdot \mathrm{kg}^{-1} \cdot \mathrm{mmHg}^{-1}($ Rippe and Grega, 1978). Whole body estimates for fetal sheep were $0.8 \mathrm{ml} \cdot \mathrm{min}^{-1} \cdot \mathrm{kg}^{-1} \cdot \mathrm{mmHg}^{-1}($ Brace and Gold, 1984). 
Single capillary studies in mammals have yielded a wide range of hydraulic conductivities, depending on the species, tissue or distance along the capillary bed. As reviewed by Michel (1984), they range from 2 to $66 \times 10^{-7} \mathrm{~cm} \cdot \mathrm{s}^{-1} \cdot \mathrm{cmH}_{2} \mathrm{O}^{-1}$ as averages of many measurements. The expected transition of lower to higher HC from arterial to venous capillaries is seen as expected. The low range of values are from rat cremaster muscle (1.0) and arterial rabbit omentum (2.0). The high range of values are from venous intestinal muscle (66) and venous omentum (44-46) of rabbit.

There is only one estimate for HC from birds. McDonagh and Gore (1978) presented values of 160 and $59 \times 10^{-7} \cdot \mathrm{cm} \cdot \mathrm{s}^{-1} \cdot \mathrm{cmH}_{2} \mathrm{O}^{-1}$ for avian postural and locomotor muscle, respectively. This is surprising in view of the fact that birds have extremely high arterial pressures and low COP. It is interesting to note that red muscle has a $\mathrm{HC}$ value $3 \mathrm{x}$ that of white muscle.

Estimates for hydraulic conductivity in amphibians have only been reported in single capillary studies, except for an isolated hindlimb preparation reported by Smits and Ilowite (1989). This estimate showed a CFC of 1.59 $\mathrm{ml} \cdot \mathrm{min}^{-1} \cdot \mathrm{kg}^{-1} \cdot \mathrm{mmHg}^{-1}$, which is much higher than any corresponding mammalian values. $\mathrm{HC}$ in single mesenteric capillaries range from 0.1 to $40 \times 10^{-7}$ $\mathrm{cm} \cdot \mathrm{s}^{-1} \cdot \mathrm{cmH}_{2} \mathrm{O}^{-1}$ with a mean of 2.5 and an increase in $\mathrm{HC}$ from arteriolar to venular capillaries (Meyer and Huxley, 1990; Meyer et al., 1992). These numbers seem low 
relative to the mammalian values, and are on average lower than those reported in a review by Michel (1984). These other values were obtained using several techniques and the range is only 2.0 to 11.3 , so these numbers are assumed to be representative of those in the literature as a whole. They are lower on average than mammalian values. However, since the diameters of the capillaries are 8 versus 20 $\mu \mathrm{m}$ (64 versus $400 \mu \mathrm{m}^{2}$ cross sectional area) for mammals and amphibians respectively, and $\mathrm{HC}$ is based on a per surface area, one might conclude that a single amphibian capillary is leakier than a single mammalian capillary. This same argument is what makes the avian numbers as discussed above even more perplexing.

In single vessel studies on Rana temporaria (Crone and Christensen, 1981), measuring electrical resistance, the average resistance was $3.0 \Omega \mathrm{cm}^{2}$ for arteriolar caps, and 0.95 for mid to venular caps. Little comparative data exists for these resistance measurements.

\section{FILTRATION IN SPECIFIC SYSTEMS}

Skeletal muscle is the most prevalent tissue in most vertebrates and thus its characteristics are highly correlated to whole-body filtration. In skeletal muscle, due especially to its abundance, substantial amounts of fluid can be mobilized from or added to the interstitial space of skeletal muscle with only small alterations of tissue fluid pressure. This depot is 4-5 liters in man (Eliassen et al., 1974). 
Cardiac tissue is a unique, critical and highly specialized tissue in which it is especially crucial to avoid increased diffusional distances during edema. Mass specific CFC and protein extravasation are especially high due to the extreme capillary densities (Laine and Allen, 1991). Blood and lymph undergo rhythmic compression and decompression with each heart beat, and this flux over time makes traditional analysis of filtration difficult.

As shown by Laine and Granger (1985), rearranging Starling's fluid flux equation yields

$$
\mathrm{C}_{\mathrm{l}} / \mathrm{C}_{\mathrm{p}}=\left[(1-\sigma)+\mathrm{L}_{\mathrm{p}} \mathrm{S} / \mathrm{J}_{\mathrm{V}}\right] /[1+\mathrm{PS} / \mathrm{Jv}]
$$

where $C_{l}$ and $C_{p}$ represent the plasma protein contrations of lymph and plasma, respectively. By inspection, we see that as $J_{V}$ (filtration) increases, $C_{l} / C_{p}$ will decrease and approach ( $1-\sigma)$. Thus, with a high reflection coefficient $(\sigma)$, at high filtration rates "washout" occurs, meaning lymphatic protein concentration will become very small in relation to plasma protein concentrations, concurrent with a removal of existing lymph.

This was demonstrated by Laine and Granger (1985) in canine myocardium by increasing coronary sinus pressure and seeing a consequent fall in $C_{1} / C_{p}$. Similarly, obstruction of lymph flow resulted in an increase in $\mathrm{C}_{\mathrm{l}} / \mathrm{C}_{\mathrm{p}}$ (Stewart et al., 1996). 
The interstitium of the myocardium has a relatively low compliance and relatively high interstitial pressures (Laine and Allen, 1991). This was demonstrated by obstruction of myocardial lymph flow in canine myocardium, resulting in an increase in interstitial pressure from 15 to $27.6 \mathrm{mmHg}$ (Stewart et al., 1996).

Thus, there are three pronounced defenses in the heart to prevent edema: dilution of interstitial protein, high interstitial pressure, and increased lymph flow. These factors interact for the necessary prevention of edema in cardiac tissue.

The pulmonary circuit in higher vertebrates is subject to much lower pressures than is the systemic circuit, thus overall filtration is much lower due primarily to the relatively low hydrostatic forces and equivalent COP to the systemic circulation. It is especially important to avoid edema, as it increases diffusional distances for oxygen and carbon dioxide. Lymphatic removal of interstitial fluid increases with increased filtration rates.

In turtles, a combination of forces during ventilation results in net filtration of fluid into the lung interstitium at rates 10-20 times those in mammals, while net absorption occurs during apnea (Burggren, 1982).

In nervous tissue, the interendothelial junctions are especially tight. They only allow small molecules to pass into the brain tissues (Guyton and Hall, 1996). Serotonin increases permeability to small molecules, as was established for cerebral postcapillary venules of frog using single-vessel methods. The effect is a rapid, dose-dependent reaction and fully reversible in a dose-dependent manner (Crone, 
1986; Oleson and Crone, 1984). This appears to be modified by endothelial cells via a 5-hydroxytryptamine receptors. Hypoxia appears to increase the permeability of the błood-brain barrier (c.f. Crone, 1986).

In the capillaries of the renal system, filtration is highly specialized for the removal of metabolic wastes. In the glomeruli, a convoluted capillary ball, the endothelial cells have small oval windows, called fenestrae, which allow large amounts of substances to be filtered without having to pass through the interendothelial clefts. Normally, plasma proteins do not traverse this barrier (Guyton and Hall, 1996).

In the sinusoidal capillaries of the liver, clefts between the capillary endothelial cells are open, such that most of the dissolved substances can pass by convection into the liver tissues. Again, this is a highly specialized tissue for processing metabolites contained in plasma.

In the intestinal mucosa of the digestive system, capillaries are relatively leaky to proteins, thus reabsorption will be low. Although not as leaky as the liver or kidney, they are much more leaky than muscle (Guyton and Hall, 1996).

In canine subcutaneous adipose tissue, Linde et al. (1974) found that sympathetic nerve stimulation increased microvascular membrane permeability as a whole. This happened despite vasoconstriction and consequent decrease of surface area. During maximal vasodilation by papaverine, filtration still increased. 


\section{THE MICROVASCULAR MEMBRANE AND THE INFLAMMATORY}

\section{RESPONSE}

Passage across the microvascular membrane is primarily passive. Indeed, transport of D-glucose through the cerebral endothelium is the only active process documented to occur across the microvascular membrane (Crone, 1965). This passivity led investigators to believe that the system was fairly static. However, the high variability in HC, filtration rates and solute-specific transport within individual capillaries and between capillary beds is remarkable. As noted above, single capillary methods of measuring $\mathrm{HC}$ are ideal for studying these pathways, and excellent reviews can be obtained from Crone and Levitt (1984), Michel (1984), Gore and McDonagh (1980) and for amphibians in particular, Curry (1986).

Microvascular filtration of both water and solutes is a combination of diffusive, convective and vesicular processes. Water crosses by a route not available to small hydrophilic molecules; thus the microvascular membrane has a combination of pathways for water and solute transport, both transmembrane and between adjacent endothelial cells. The transmembrane channel for water accounts for approximately $10 \%$ of the total hydraulic conductivity, and the shared channel for water and these hydrophilic molecules supports the additional 90\% (Curry et al., 1976).

Selectivity of the capillary wall is inconsistent with the $\mathrm{HC}$ and small solute exchange observed, leading to the theory that interendothelial junctions are 
regulated by a fibrous network of plasma proteins, primarily albumin (Curry, 1986). Such a model of interendothelial junctions is consistent with the reflection coefficient such that larger plasma proteins are selectively prevented from crossing the capillary wall. This has been experimentally confirmed by the observation that a perfusate of protein-free Ringers has a higher $\mathrm{HC}$ than a perfusate with normal protein concentrations or even levels well below physiological levels (Mason et al., 1977 c.f. Gore and McDonagh, 1980; Huxley and Meyer, 1990) and by observations of marked albumin and glycocalyx of endothelial cells (Ryan, 1986).

Histamine, a biogenic amine released from mast cells, basophils, and platelets (Guyton and Hall, 1996) is a known mediator of the inflammatory process in mammals. An excellent review of this process can be found in Grega (1986). The inflammatory response is also referred to as the mediator-stimulated pathway which has several effectors other than histamine including autocoids, anaphylatoxins, free radicals, immune complexes and activated leukocytes as reviewed by Grega (1986). The receptor mediated pathway does not effect the pulmonary capillary beds (Guyton and Hall, 1996) which are especially sensitive to edematous fluid increasing the diffusional distances for oxygen and carbon dioxide.

A series of experiments on the isolated canine limb by Grega et al. (1972, 1980, 1986; Marciniak et al., 1978) have led to an understanding of the mediator-stimulated pathway. In their preparations, histamine produces a dramatic protein efflux, increase in hydraulic conductivity, and consequent onset of edema 
due to elimination of the colloid gradient. This is further accentuated by the hemodynamic actions of histamine (vasodilation) which increases blood flow to the capillary bed. This edematous state increases lymph formation and return. The hemodynamic actions are maximal at the lowest concentrations of $1 \mu \mathrm{g} /$ minute, while protein efflux increases beyond that in a dose-dependent manner. Vasodilation also tends to lower arterial pressures under natural flow conditions, as more capillary beds are perfused. This effect is transient due especially to the release of catecholamines by the adrenals with decreasing arterial pressures if histamine is widespread. Thus, during hypotensive states, locally infused histamine is without effect. During anaphylactic shock, with widespread histamine release, epinephrine is used to counteract the loss of plasma to the interstitium to avoid circulatory shock. These antagonize the effects of histamine, but even with prevention of these by isolation of the hind-limb efflux, the effect only lasts no more than 30 minutes. While continuously administered norepinepherine almost totally exterminates the response, isoproteronol (a $\beta$-adrenergic agonist) reduces lymph flow, and presumably the rate of filtration, to nearly one-third of the inflammatory state. The independence of the inflammatory response to the vasoactivity of histamine was demonstrated by the addition of angiotensin, a profound vasoconstrictor. Angiotensin failed to affect the histamine response (Grega et al, 1980). Vasopressin, serotonin, and high concentrations of glucocorticoids counteracted the inflammatory response of histamine (Grega et al, 
1980), but failed to effect its hemodynamic effects, again demonstrating that the two processes are independent of each other.

Phentolamine, an $\alpha$-adrenergic antagonist, failed to alter the antagonism of the histamine induced protein efflux by norepinephrine or isoproteronol, while maintaining the hemodynamic actions. Propanolol blocks all $\beta$-adrenergic receptors, but not $\alpha$-adrenergic receptors. Pretreatment with propanolol prevented the antagonism of norepinephrine on protein efflux by histamine.

This is supported by work using rat hindquarters, where histamine was used on maximally dilated capillary beds via papaverine (Rippe and Grega, 1978). This induced an increase in CFC from a controi of 0.483 to $1.32 \mathrm{ml} \cdot \mathrm{min}^{-1} \cdot \mathrm{kg}^{-1} \cdot \mathrm{mmHg}^{-1}$ with histamine infusion, again establishing the independence of the change in microvascular permeability from vasoactive effects. Infusion of isoproteronol returned $\mathrm{CFC}$ to near control values. The preparation remained refractory to histamine for a subsequent period (30-60 min.). Permeability to small molecules was not significantly altered from control during the histamine infusion using Cr-EDTA. Cooling of the hindquarters to 10 to $15^{\circ} \mathrm{C}$ reduced the initial values of CFC to $0.281 \mathrm{ml} \cdot \mathrm{min}^{-1} \cdot \mathrm{kg}^{-1} \cdot \mathrm{mmHg}^{-1}$. This value increased with histamine to $0.451 \mathrm{ml} \cdot \mathrm{min}^{-1} \cdot \mathrm{kg}^{-1} \cdot \mathrm{mmHg}^{-1}$, a smaller increase than seen at warmer temperatures. 
These studies further illustrate the mediator-stimulated pathway is antagonized by $\beta$-adrenergic receptors which are independent of the mediator (histaminic) receptors̀ (Rippe and Grega, 1978). Vesicular transport of macromolecules by mediator-stimulated pathways is not likely, as a concurrent increase in CFC would not be expected.

Venular large functional gap formation is now known to be a characteristic feature of the inflammatory process (Grega, 1986). These gaps are approximately 1 $\mu \mathrm{m}$ in diameter and are believed to be produced by a rounding up of the ends of adjacent endothelial cells, due to a contraction of actomyosin-like anchoring filaments. Cooling of the tissues caused less of an increase in CFC and presumably the size of these gaps, which is consistent with microcontractile processes (Rippe and Grega, 1978). The combination of these facts suggest that the catecholamines, by stimulation of $\beta$-adrenergic receptors, cause relaxation of these contractile filaments. As noted by Rippe and Grega (1978), it is interesting to speculate that cold applied to swelling reduces edema, maybe not just by reducing blood flow, but by reducing the number or size of venular gaps.

From this work, Grega (1986) concluded that "the mediator-stimulated macromolecular transport pathway is an energy-dependent, receptor activated system subject to direct regulation". A dual large and small pore system was envisioned with static small pores, the interendothelial junctions, and variable large pores with variable hydraulic conductivities. 
Similarly, whole organ studies have shown that at high pressures, the flux of macromolecules is accounted for by the same channels as water flow through a smalt.population of larger pores (Taylor and Granger, 1984). These may or may not be the same variable large pores as involved in the histamine response.

Majno et al. (1969), studying the mediator-stimulated pathway in rat cremaster muscle, first hypothesized that endothelial cells possess receptors that elicit contraction of the cells. This leakage of macromolecules was proposed to be due to contractions of vascular elements such that gaps of up to $1 \mu \mathrm{m}$ in diameter open up between endothelial cells.

Miller and Sims (1986) present an excellent review of the mechanisms of the microvascular membrane. Many agents that affect smooth muscle tone also affect macromolecular leakage, thus producing the hemodynamic effects described above. The primary target is small venules. Mediators produce interendothelial gaps in venules and changes in the shape of the endothelial cell, properties not due to the smooth muscle itself .

Pericytes encircle small arterioles, capillaries and most venules and are found in a wide variety of species and tissues. They are long, irregular cells averaging $77 \mu \mathrm{m}$ in length, as characterized in rat skeletal muscle, with two or more major processes and many cytoplasmic branches. They differ depending on location, both between tissues and within the length of a capillary bed. They are clustered and more numerous in the postcapillary venules. 
Whether the formation of venular gaps is due to the pericytes or endothelial cells is unknown. Endothelium and pericytes have been shown to contain many of the same elements of the contractile machinery present in smooth muscle. Pericytic processes sometimes end near endothelial junctions and there is an abundance of fibronectin anchoring them to the endothelium.

Calcium has been implicated as the possible modulator of these interendothelial gaps. Calcium ionophores increase the permeability of the microvascular membrane, while cytosolic calcium modulates junctional permeability (DeMello, 1984 c.f. Crone, 1986). Plasmalemmal invaginations of pericytes have been observed, and these infoldings may allow fast communication between the cell interior and exterior for effectors such as calcium (Crone and Christensen, 1981). This could let in calcium which could act on either pericytes, endothelial cells or both. Histamine receptors have been found on endothelial cells (Heltianu et al., 1982 c.f. Miller and Sims, 1986), but this does not preclude pericytes from being the effector. This type of cell communication is found between smooth muscle and endothelial cells via agonists not acting directly on smooth muscle cells. It is likely that receptor mediated effects and the effects on cytosolic transducer systems occur via a common final pathway that seems to be a calcium-dependent mechanism, probably leading to activiation of the actin-myosin filaments, as in smooth muscle (Crone and Christensen, 1981; Crone, 1986). 


\section{ATRIAL NATRIURETIC PEPTIDE}

Atrial natriuretic paptide (ANP) is a recently discovered hormone, first characterized by deBold et al. (1981 c.f. Glass et al., 1996) from atrial tissue. Although the name of this hormone implies exclusive renal function, it has been demonstrated to have an effect on filtration in several species. ANP is released under hypervolemic conditions, such as distension of the atria (Lang et al., 1989). ANP has been shown to decrease plasma volume (Sugimoto et al., 1989) independently of renal functions, causing plasma volume reductions in human subjects greater than renal losses (Lee and Goldman, 1989; Biollaz et al., 1986 c.f Meyer and Huxley, 1990) and causing equivalent plasma losses in nephrectomized and sham operated rats (Almeida et al., 1986 c.f. Meyer and Huxley, 1990; Fluckiger et al., 1986) with a proportional rise in large vessel hematocrit (Fluckiger et al., 1986). It has been demonstrated to depress arterial pressure and cardiac output (Goets, 1988; Lee and Goldman, 1989). ANP operates by a redistribution of microvascular blood flow (Sarelius and Huxley, 1990; Trippodo and Barbee, 1987) and increases HC and permeability to plasma proteins (Tucker et al., 1992) in mammals. Tracer studies show that accumulation of albumin in specific tissues is increased from 2-4 times under pathophysiological ranges. This extravasation of albumin does not go through the large gaps of the mediator-stimulated pathway, although the mechanism of extravasation is unknown. 
Under various physiological and pathological conditions, ANP in mammals is seen from 3-30 picomoles (Goets, 1988; Lang et al., 1989) at rest and as high as several hundred picomoles (Epstein et al., 1986; Arendt et al., 1986 c.f. Meyer and Huxley, 1990) during various hypervolemic states.

In rainbow trout (Oncorhyncus mykiss), plasma levels of $17.25 \mathrm{pg} / \mathrm{ml}$ during volume loading with maximal release levels of $200 \mathrm{pg} / \mathrm{min} / \mathrm{kg}$ body mass, 24 times the release during control perfusion. The atrium contains $92 \%$ of ANF in the heart and ANF release is more sensitive to hemodynamic changes on the venous rather than the arterial side of the heart. (Cousins and Farrell, 1996).

ANP has been found to be highly conserved throughout evolution. ANP-like peptides have been found in a single celled organism Paramecium multimicronucleatum (Vesely and Giordano, 1992 c.f. Glass et al., 1996) and is very similar amongst highly divergent species such as frogs and rats (Glass et al., 1996). It has been measured and documented in many vertebrates and it has been isolated throughout the mammalian species including human, rat, rabbit, bovine, etc. (see Renkin and Tucker, 1996 for a review) as well as in birds, reptiles, amphibians (Baeyens et al., 1989; Gutkowska and Nemer, 1989; Gilles et al., 1990; Glass et al., 1996; Netchitailo et al., 1987 c.f. Glass et al., 1996) and fish (Cousins and Farrell, 1996). Levels of ANP correspond to seasonal changes in some animals. Plasma levels of ANP decrease significantly during hibernation in marmots (Zatsman and Thornhill, 1989). 
ANP has been documented to be physiologically active in ectotherms. In reptiles, ANP release increases in the turtle during diving (Baeyens et al., 1989). In single capillaries of frogs, ANP increases HC (Meyer and Huxley, 1990; Meyer et al., 1992), although Clough (1988 c.f. Meyer et al., 1992) found this effect only in venular capillaries. The release of ANP due to volume loading was demonstrated in rainbow trout (Cousins and Farrell, 1996). A seasonal effect was also found by Huxley and Curry (1995) in Rana pipiens. A peak hydraulic conductivity was described for venular capillaries in August, while hydraulic conductivity in arteriolar capillaries peaked in May. Both had a low HC in January, while "true" mid-capillaries were relatively constant throughout the year. ANP reactivity was minimal in May and enhanced in October.

ANP synthesis and receptors have been found in a number of extra-atrial tissues. For a review of these, see Gutkowska and Nemer (1989). It is synthesized in the pituitary, adrenal, gut and pancreas. Receptors of ANP generally correlate with synthesis of ANP, so an autocrine or paracrine role can be imagined. ANP synthesized in heart ventricles and lung may contribute to plasma ANP levels, particularly in pathophysiological conditions, but the low level found in other tissues has yet to be assessed. ANP in nervous tissue suggests a second role either in neurotransmission or as a neuromediator. ANP presence in fetal tissue has yet to be explored. 
A set of experiments was done to analyze the effects of ANP in frog mesenteric capillaries (Rana pipiens) using the single-vessel approach (Meyer and Huxley, 19.90; Meyer et al., 1992). Using washed human erythrocytes as markers and a Ringers perfusate with BSA concentrations of $10 \mathrm{~g} / \mathrm{L}$, These workers first established $\mathrm{HC}$ control values ranging from 0.1 to $40 \times 10^{-7} \mathrm{~cm} \cdot \mathrm{s}^{-1} \cdot \mathrm{cmH}_{2} \mathrm{O}^{-1}$ with a mean of $2.5 \times 10^{-7} \mathrm{~cm} \cdot \mathrm{s}^{-1} \cdot \mathrm{cmH}_{2} \mathrm{O}^{-1}$. $\mathrm{HC}$ values varied widely throughout this range. They demonstrated a transition from arteriolar to true to venular capillaries with mean values of $0.9,2.2$ and $5.8 \times 10^{-7} \mathrm{~cm} \cdot \mathrm{s}^{-1} \cdot \mathrm{cmH}_{2} \mathrm{O}^{-1}$, respectively. No correlation between vessel diameter (mean values of 16,19 and $25 \mu \mathrm{m}$, respectively) and $\mathrm{HC}$ was found. Using human ANP, they found a direct reversible elevation of single capillary $\mathrm{HC}$ with exposure to as low as $10 \mathrm{pM}$ ANP ranging up to $100 \mathrm{nM}$ ANP. The greatest sensitivity occurred in the venular capillaries ( 2.4 times control), sensitivity in true capillaries (2.2 times control) and no significant effect of ANP on arteriolar capillaries again with a wide variety of responses. Response was also conveyed as the percentage of capillaries exhibiting a twofold change from control values, where $60 \%$ of combined venular and true capillaries exhibited such a response, while only $25 \%$ of arteriolar capillaries exhibited such a response (Meyer and Huxley, 1990).

In an additional set of experiments (Meyer et al., 1992), these same workers demonstrated a receptor dependent $\mathrm{HC}$ response to ANP in chronically volume- 
expanded animals immersed constantly in fresh water. This volume expansion was confirmed by a lowered hematocrit and lowered plasma protein concentrations which indicated a $30 \%$ blood volume expansion compared to animals with free access to water (the condition from the experiment above) and limited access to water (stored on damp sand). These non volume-expanded animals showed a characteristic (Meyer and Huxley, 1990) 3.2 fold elevation of HC in response to ANP versus control values, while chronically expanded animals only showed a 1.3 fold elevation in response. These same volume expanded animals retained their response in $\mathrm{HC}$ to sodium nitroprusside (2.7 fold response). The ANP-R1 receptor acts to elevate cyclic-GMP levels, as opposed to the other ANP receptors which act to elevate cyclic-AMP. Sodium nitroprusside acts to elevate cyclic-GMP accumulation (Murad et al., 1979 c.f. Meyer et al., 1992) independently of the ANP-R1 receptor. Thus, the ANP response in the capillaries of these animals was classified as ANP-R1 receptor dependent. For a review of ANP receptors, see Aranjaniyil et al. (1987) and Tucker et al. (1995).

Recently, ANP synthesis has been characterized in the lung of the toad, Bufo paracnemis, as well as all of the receptors on which ANP operates (Glass et al., 1996). It exists there in levels twice as high as levels in similarly sized mammals, and thus the function of ANP in amphibians now includes a possible role in avoidance of lung edema. Studies by Imamura et al. (1988, c.f. Glass et al., 1996) suggest that ANP aids in prevention or alleviation of edema in mammalian 
lung. Outside of individual capillary studies however, the mechanism of ANP in anurans as a physiological mechanism has evaded detection. Renal function does not appear to be changed (Stanley S Hillman; .unpublished data), nor does there appear to be any effect on the lymphatic hearts (Edward DeGrauw, unpublished data).

\section{GRAVITATIONAL CHALLENGE}

Gravity poses a severe hydrostatic challenge to long or tall animals such as snakes, humans and giraffes. Plasma fluid loss due to gravitational hydrostatic forces has possibly been underestimated in humans. Bjerkhoel and Lundvall (1995) have shown a large tissue gain in interstitial fluid in the thigh and buttocks due to standing. These are the primary areas of filtration, as opposed to the foot and calf, due simply to the greater tissue mass. This fluid loss may have been previously underestimated due to the pooling of hemoconcentrated blood in the venous compartments of the leg during standing, while the approach of Bjerkhoel and Lundvall (1995) measured increases in hematocrit after resumption of the supine position and equilibration of blood with an extrapolated hematocrit estimate. This same approach measured declines of no less than $11.7 \mathrm{ml}$ of plasma over 5 minutes translate into a CFC of 0.08 to $0.10 \mathrm{ml} \cdot \mathrm{min}^{-1} \cdot \mathrm{kg}^{-1} \cdot \mathrm{mmHg}^{-1}$ (Lundvall et al., 1996). As stated above, the body shape of a snake dictates large gravitational gradients during head-up or head-down tilting. Increased peripheral resistance is a 
dominant reflex in pressure adjustments to tilting in terrestrial snakes and mobilization of extravascular fluids in response to hemorrhage is extremely effective (Lillywhite and Smith, 1981). Interstitial compliance also varies interspecifically when comparing terrestrial to arboreal snakes. Arboreal species possess lower interstitial compliances than do terrestrial snakes (Lillywhite, 1993b). This quality would help them resist excess filtration, especially if snakes do indeed possess a high CFC, which is implied by their ability to mobilize fluids to the blood volume from the interstitium quickly during hemorrhage. Postural shifts of fluid from extravascular to vascular compartments of terrestrial snakes are three times greater than in arboreal species when subjected to tilting (Lillywhite, 1985). Concurrent with this information, aquatic and some terrestrial snakes are extremely intolerant of gravitational forces during tilt and are unable to compensate beyond moderate tilting for long periods of time (Lillywhite, 1993a). This is most likely due to a high CFC, high interstitial compliance or a combination of both as well as an inability to regulate vasomotor tone to a sufficient degree, resulting in blood pooling in lower regions and lack of blood flow to the brain.

\section{HYPOVOLEMIC CHALLENGE}

Mammals are relatively intolerant of hemorrhage or dehydration. Blood losses in excess of 35-50\% result in irreversible shock (Guyton and Hall, 1996). Still, a remarkable capability for sympathatic tone results in a return of vast 
amounts of fluid from the interstitium, primarily skeletal muscle. Very little of this process is passive reabsorption and up to $70 \%$ of the reabsorptive capacity is due to increased motor tone as studied in cat skeletal muscle (Hillman, 1981) resulting in a drop in capillary pressure, due primarily to catecholamine release from the adrenals (Lundvall and Hillman, 1978; Hillman and Lundvall, 1981). These affect the capillary pressure by mediating vasodilation in the post-capillary venules via $\beta$-adrenergic receptors and a concomitant vasoconstriction of pre-capillary sphincters via $\alpha$-adrenergic receptors. This also leads to an increase in capillary surface area for reabsorption. With $\beta_{2}$-adrenergic blockade, volume recovery was only $19-20 \%$ of that with functioning $\beta$-adrenergic receptors (Hillman and Lundvall, 1981).

Another avenue for mobilization of extravascular fluids during hemorrhage in mammals may lie in the development of hyperglycemic hyperosmolality within the circulation due to release of glucose from the liver, increasing the COP in favor of reabsorption (Ware et al., 1980 c.f. Smits and Lillywhite, 1985).

Studies of fetal sheep reflect a high whole body interstitial compliance and consequently high capillary filtration coefficient compared with the adult. The fetus has the ability to decrease vascular compliance and surface area after hemorrhage. Consequently, the fetus has a large capacity for restoration of lost volume after 
hemorrhage ten times faster than that in adults. Autonomic blockade slows this response (Brace and Gold, 1984).

Snakes pose an especially interesting blood volume regulatory model, as their body shape dictates large gravitational gradients during head-up or head-down tilting. Increased peripheral resistance is a dominant reflex in pressure adjustments to tilting in terrestrial snakes, and mobilization of extravascular fluids in response to hemorrhage is extremely effective. Possible regulation of venomotor tone can be inferred from the stability of central venous pressure during hemorrhage, which suggests that venous capacity is preferentially reduced in response to blood loss (Lillywhite and Smith, 1981). Snakes as a whole are able to tolerate extreme hemorrhage, up to $100 \%$ of their initial blood volume (Smits and Lillywhite, 1985; Lillywhite and Pough, 1983). During hemorrhage sea snakes adjust their blood volume extremely rapidly, despite having relatively poor to absent baroreceptor reflex adjustment of vasomotor tone, as demonstrated by their ineffective response to tilting outside of water (Lillywhite and Pough, 1983). This lack of autonomic adjustment abilities in conjunction with the ability to mobilize fluid from the extravascular space implies an especially high CFC in sea snakes. Blood volume is reduced $20-25 \%$ during activity in both Elaphe obsoleta and Crotalus viridis (Lillywhite and Smits, 1984), also suggestive of a high CFC in snakes. Relatively low arterial pressures and consequently lower capillary hydrostatic pressures, exceptionally large extravascular volume relative to other vertebrates and the 
compliances of their vascular and interstitial spaces (Smits and Lillywhite, 1985) also contribute to this ability.

Birds also have been shown to have a high capacity for blood volume maintenance due to reabsorption from the interstitial spaces probably due to vasoconstriction in skeletal muscle, resulting in an increased pre- to post-capillary resistance ratio yielding a drop in hydrostatic pressure (Djojusugito et al., 1968), despite a relatively high arterial pressure in comparison to other classes of vertebrates.

The extreme hypovolemic tolerances of anuran amphibians are well documented (Middler et al., 1968; Hillman, 1980; Hillman and Sommerfeldt, 1981; Hillman, 1987; Hillman and Withers, 1988; Withers et al., 1988; Hillman, 1991; Jones et al., 1992; Baldwin et al., 1993), whether induced by dehydration or by hemorrhage. This tolerance is better demonstrated by terrestrial species than aquatic. An exceptional example is Bufo marinus which can withstand losses of up to $30 \%$ of their initial body weight, or roughly $400 \%$ of their original blood volume, to dehydration.

Lymph hearts in anurans are essential for regulating blood volume during hypovolemia. With intact lymph hearts, activity induced no change in hematocrit in Rana pipiens while arterial pressure increased from 26 to $33 \mathrm{mmHg}$. Lymph heart rates increased from 86 to $113 \mathrm{bpm}$. Any increase in filtration was compensated for by an increased lymphatic activity (Baldwin et al., 1993). 
Baustian (1988) showed that reabsorption alone cannot maintain blood volume in Bufo marinus without functioning lymph hearts. Electro-cautery of the lymph hearts and hemorrhage resulted in eventual death of the animal, where sham-operated animals were able to tolerate the same hemorrhage. This was confirmed by Baldwin et al. (1993), where stoppage of lymph hearts via anaesthetization followed by hemorrhage increased hematocrit from 26 to $43 \%$ in Rana pipiens. This was primarily attributable to a loss of plasma volume and no change in COP. Middler et al. (1968) made these same comparisons in nephrectomized and hypophysectomized toads with the same results, thus eliminating nephrostomal uptake as the avenue of extravascular mobilization, and suggesting a peripheral mechanism for increased lymphatic uptake. It was also demonstrated that significant shifts from intracellular compartments did not take place for several hours.

During dehydration, osmotic forces are shifted with an increase in hematocrit and the concentration of plasma proteins. Jones et al. (1992) using Bufo marinus demonstrated a lymph flow decrease to nearly zero during dehydration from a hydrated rate of $0.185 \mathrm{ml} \cdot \mathrm{min}^{-1} \cdot \mathrm{kg}^{-1}$. Thus, they are capable of adapting their lymph heart activity to changes in interstitial fluid volume.

Hillman et al. (1987) compared the transcapillary fluid forces during dehydration in Bufo marinus and Rana catesbeiana, a relatively dehydration tolerant terrestrial species with a relatively dehydration intolerant (within anurans) 
aquatic species, respectively. Both species lost mass at about the same rate per day (5-9\%). Sodium increased in proportion to blood volume lost. Hematocrit increased proportionally in Rana while it remained constant in Bufo, until mass losses exceeded $12 \%$, from whence blood volume decreased until $24 \%$ mass loss, after which it decreased proportionally to water loss. This effect in Bufo essentially delayed hypovolemia and hyperviscosity. Plasma protein concentration increased in both species with dehydration, more than would be predicted by passive concentration; thus protein had to be preferentially added to the vascular space from some extravascular source via the lymphatics. Venous pressure was maintained during dehydration, implying significant control of vasomotor tone. Interstitial pressures were found to be slightly negative. Analysis of these variables in relation to the fluid flux equation yielded a tendency for ultrafiltration throughout dehydration for Rana and for filtration in Bufo up until dehydrational losses exceeded $25 \%$ of body mass. These findings confirmed dependence upon the lymphatics for mobilization of extravascular fluid and invalidated reabsorption as a possible mechanism of mobilization.

In another study by the same workers inducing hemorrhage on the same species (Hillman and Withers, 1988), maximal blood flow rates were found to be compromised in Rana at $2 \%$ loss of body mass, while Bufo retained control rates until 5\% loss of body mass. Over a larger series of anurans, Hillman (1980) 
correlated dehydrational tolerance with tolerance to high sodium concentration, as well as ventricle weight and initial plasma volume.

\section{STATEMENT OF PURPOSE}

Transcapillary filtration is an important component of body water homeostasis and is virtually unexplained in amphibians beyond the single capillary level. Hydraulic conductivity is highly variable in different organ systems; different organs; individual capillary beds; individual capillaries and along the length of an individual capillary. While single vessel methods are powerful techniques for detecting the mechanisms operating within the microvascular membrane, their extreme ranges of variability between venous to arteriolar capillaries of factors up to 11 times (Crone and Christensen, 1981; Curry, 1979; Mason et al., 1977; Fraser et al., 1978) allow little extrapolation to the tissue level, much less the organismic level.

At the present time, rates of whole body transcapillary filtration in anuran amphibians are unknown. Quantification of this process may lead us to a better understanding of the process of body water homeostasis in amphibians. Accounting of the interspecific differences between Bufo marinus and Rana catesbeiana, two differentially dehydration tolerant species, may further clarify these processes. It is hypothesized that Bufo marinus, the more dehydration tolerant of the two, would 
conserve its blood volume more efficiently, which may result in a lower hydraulic conductivity of capillary vessels. 


\section{METHODS AND MATERIALS}

Cane toads (Bufo marinus; $\mathrm{n}=7$; range $=0.185 \mathrm{~kg}-0.350 \mathrm{~kg}$; mean $=0.259 \mathrm{~kg}$ ) and bullfrogs (Rana catesbeiana; $\mathrm{n}=5$; range $=0.358 \mathrm{~kg}-0.721 \mathrm{~kg}$; mean $=0 . .473 \mathrm{~kg}$ ), hereafter termed toads and frogs respectively, were purchased from commercial suppliers and housed in plastic garbage cans and high-sided plastic trays respectively, with free access to water. Experiments were performed during the months of June and July of 1997 using both males and females. All experiments were conducted at room temperature $\left(22 \pm 2^{\circ} \mathrm{C}\right)$. No attempt was made to control photoperiod or feed the animals, which were used within 1 to 8 weeks of arrival in the lab.

Anesthesia was achieved for the in vitro preparation with ethyl p-amino-benzoate (benzocaine) via subcutaneous injection into the dorsal lymph sac. A preparation of 0.1 grams of benzocaine was dissolved in $1 \mathrm{ml} 90 \%$ ethanol for injection. Approximately $1.5 \mathrm{ml} \cdot \mathrm{kg}$ body mass $^{-1}$ was the dosage required for frogs, resulting in an initial dosage of $0.15 \mathrm{~g}$ benzocaine $\mathrm{kg}$ body mass $^{-1}$. Toads were given an initial dosage $1.0 \mathrm{ml} \cdot \mathrm{kg}$ body mass ${ }^{-1}$, resulting in an initial dosage of $0.10 \mathrm{~g}$ benzocaine $\cdot \mathrm{kg}$ body mass ${ }^{-1}$. Experimentation began approximately $20-40$ minutes later when corneal-reflex and self-righting reflexes were lost. Bladder 
reserves were drained by cloacal cannulation and suprapubic pressure and the bladder-empty mass of the animal was recorded.

The animals were positioned with ventral side facing up and an incision was made through the skin and muscular layer laterally across the xiphisternum in frogs and below the xiphisternum in toads to expose the heart. A lateral incision of approximately $5 \mathrm{~mm}$ on either side of the xiphisternum was necessary to expose the

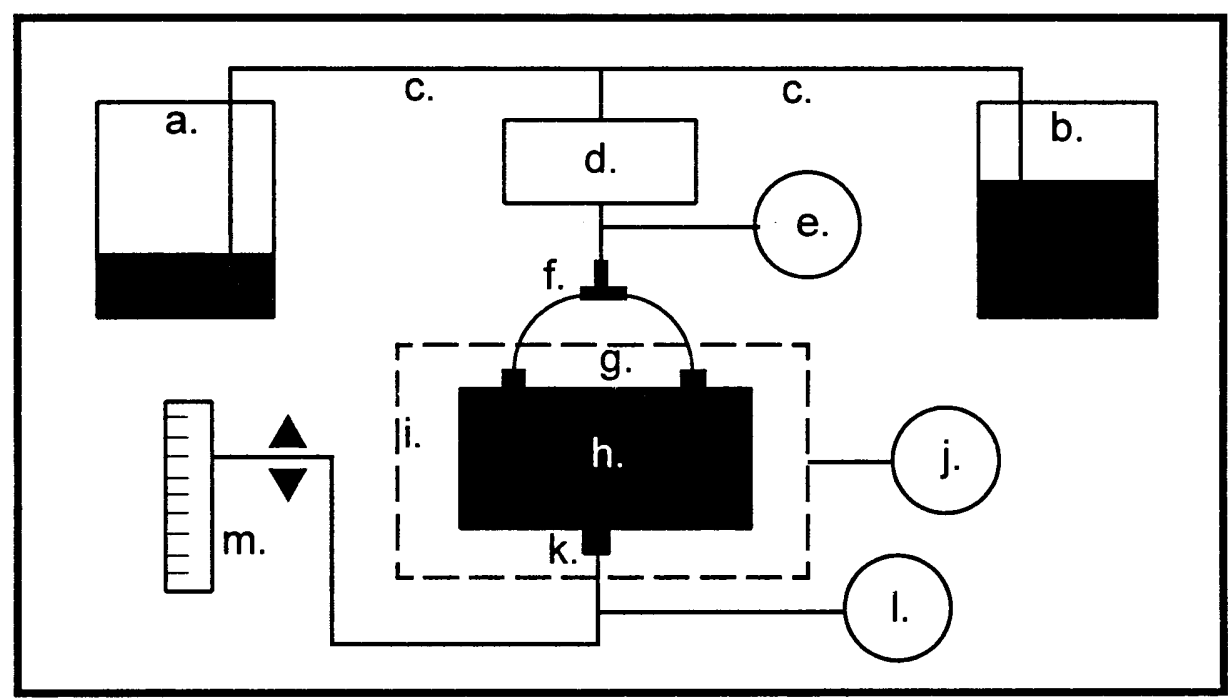

Figure 1. Schematic diagram of in vitro preparation: a. Primary reservoir containing Ringers perfusate with benzocaine; $b$. secondary reservoir containing hormone or other treatment; c. alternating tubes to draw from either reservoir; $d$. peristaltic pump to provide arterial input pressure; e. pressure transducer to monitor arterial input pressure; f. arterial input cannula with t-fitting to branch to both systemic arches; g. cannulated systemic arches with pulmocutaneous arteries occluded; $h$. systemic circulation of the animal; i. platform (represented by dotted lines) containing preparation; j. force transducer attached to platform to register mass of preparation; $k$. cannulated ventricle for venous return; $\mathrm{l}$. pressure transducer monitoring venous return pressure; $m$. venous outflow pressure regulator adjustable by vertical displacement of top of outflow cannula. 
cavity sufficiently. Any bleeding was coagulated immediately via electro-cauterization. The pericardium and any necessary connective tissue was removed to expose both the truncus arteriosus and the systemic arches up to the point where the pulmocutaneous artery diverges. Approximately $0.3 \mathrm{ml}$ of heparinized saline was injected into the ventricle of the heart to keep the system free of clots during inevitable short duration stoppages of blood flow during cannulation. Both of the pulmocutaneous arteries were occluded with nylon suture (Braunamid 3/0 sterilized non-absorbable surgical suture), which was also used for all subsequent ties. This resulted in an exclusive perfusion of the systemic vasculature, so pulmonary circulation does not contribute to any of the results. The systemic arches were cannulated with a double T-cannula (Figure 1) and tied off.

This cannulation served as the arterial input and at this point perfusion with Ringers was begun via an infusion pump (Sage Instruments, syringe pump model 351) at rates between 6 and $10 \mathrm{ml} / \mathrm{min}$. The Ringers recipe per liter deionized water consisted of $6.424 \mathrm{~g} \mathrm{NaCl}(0.110 \mathrm{M}), 0.2503 \mathrm{~g} \mathrm{KHCO}_{3}(0.025 \mathrm{M}), 0.1470 \mathrm{~g} \mathrm{CaCl}_{2}$ $(.0010 \mathrm{M}), 0.9008 \mathrm{~g}$ glucose $(0.005 \mathrm{M})$ and $0.1 \mathrm{~g}$ bovine serum albumen (BSA) and benzocaine at $1: 24,000$ ratio $(0.041 \mathrm{~g}$ benzocaine/liter) for continuous anesthetization throughout perfusion. Ringers was then adjusted to $\mathrm{pH}=7.8$.

The apex of the ventricle was then incised with an $\mathrm{x}$-shaped cut in order to insert the venous output (VO) cannula through the main portion of the ventricle and into the right atrium to receive total venous return from the systemic vasculature. 
The cannula was secured within the ventricle by nylon suture tied around the muscle of the ventricle. Systemic arches were then occluded upstream from the point of cannulation, preventing venous return from exiting the heart via the conus arteriosus, effectively isolating the system to flow from the arterial input cannula, through the systemic circulation and out the VO cannula.

Once it was established that Ringers was flowing freely through the VO cannula, the preparation was then transferred to a platform where the peristaltic pump (VWR mini-pump, variable flow) could serve as the driving device to the arterial input cannula and continue perfusion with Ringers which was continuously bubbled with pure oxygen to ensure an adequate supply of oxygen to the tissues.

The sufficient delivery of oxygen to the preparation is based upon the following. The basal metabolic rate for Bufo marinus is $0.73 \mathrm{ml} \mathrm{O} \cdot \mathrm{kg}^{-1} \cdot \mathrm{min}^{-1}$ (Withers et al., 1988). An average Bufo of $0.231 \mathrm{~kg}$ would thus require 0.169 $\mathrm{mlO}_{2} \cdot \mathrm{min}^{-1}$. The solubility of oxygen in seawater is $0.0628 \mathrm{mlO}_{2} \cdot \mathrm{L}^{-1} \cdot \mathrm{mmHg}^{-1}$ (Dejours, 1975). From this we can estimate that $10 \mathrm{ml}$ of seawater bubbled with pure oxygen ( $1 \mathrm{~atm}$ or $760 \mathrm{mmHg}$ ) would contain $0.477 \mathrm{ml}$ oxygen. At an average perfusion rate of $10 \mathrm{ml} \cdot \mathrm{min}^{-1}, 0.477 \mathrm{ml}$ oxygen would be delivered per minute as compared to the $0.169 \mathrm{ml}$ oxygen necessary for basal metabolism. This is a comfortable margin since neither saturation nor delivery are perfect. Fortunately, more oxygen will saturate in Ringers than in seawater and Rana catesbeiana has a lower metabolic rate than Bufo marinus (Hillman, 1987). 
A pressure transducer (Narco Bio Systems, Model P-1000B) was attached to monitor the arterial pressure $\left(\mathrm{P}_{\mathrm{a}}\right)$ coming into the system. The cannula was stabilized between the pump and the platform such that movement of the pump would not be transferred to the platform. Similarly, the VO cannula was attached to a pressure transducer (Narco Bio Systems, Model RP-1500) monitoring the venous pressure $\left(\mathrm{P}_{\mathrm{v}}\right)$, stabilized, and the outflow was directed to the venous outflow pressure regulator, a device which could precisely raise or lower the height of the VO cannula, thus increasing or decreasing the pressure opposing the outflow from the circulation.

The platform was suspended (Figure 2) from a hardwood board (92 x 14 x $1.5 \mathrm{~cm}$ ) which was balanced on a fulcrum to form a first class lever system. This was accomplished by placing two small nails near the center of the board on opposite sides perpendicular to the length of the board. The nails rested on narrow metal edges parallel to the length of the board on either side. A force transducer (Narco Bio Systems, Myograph F-2000) was suspended above and at the same end of the board as the platform, effectively registering the mass of the platform and the preparation within. The mass of the platform was counterbalanced by a beaker of water placed on the opposite end of the board. Water was constantly added or subtracted to or from the counterbalancing beaker until a near zero effective force was placed on the force transducer thus enabling small changes in the total mass of the animal to be registered. 


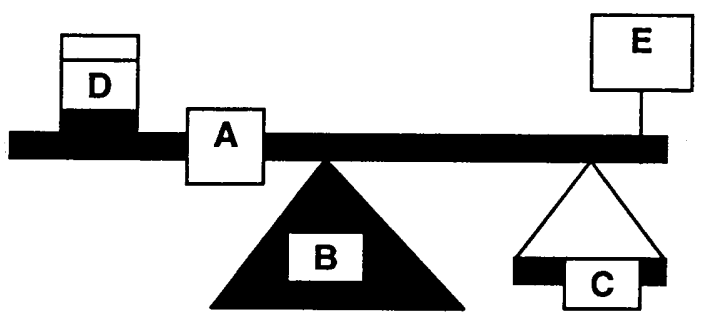

Figure 2. First class lever device used to measure small changes in mass by countering most of the weight of the preparation and making measurements at near zero effective mass. The board (a) is balanced on the fulcrum (b). The platform (c) containing the preparation is hung from one end of the board and counterbalanced by variable amounts of water placed in beaker (d). Small changes in mass of the preparation are monitored by the force transducer (e).

The arterial pressure $\left(\mathrm{P}_{\mathrm{a}}\right)$ was monitored and the flow from the peristaltic pump was adjusted to bring $\mathrm{P}_{\mathrm{a}}$ to an appropriate pressure within physiological ranges of 20-30 mmHg (Hillman and Withers, 1988; Withers et al., 1988; West and Smits, 1994), although no attempt was made to achieve a specific $\mathrm{P}_{\mathrm{a}}$ or flow. In fact, a range of $P_{a}$ was preferred in order to validate that the CFC did not change over different pressure ranges, although $\mathrm{P}_{\mathrm{a}}$ and flow were generally kept constant for each animal. Data acquisition from the two pressure transducers and the force transducer was performed by Superscope II (GW Instruments: v 2.17) on a Macintosh IIci using an amplifier (Narco Bio Systems, Model Six-B) and an Instrunet Data acquisition board (Model 100 Analog/Digital Input/Output System). Data points were acquired each $0.1 \mathrm{~s}$. Pressure transducers were calibrated before the surgery against known increases of the height of a column of water and were 
found to be linear within the ranges of pressures measured. Calibration of the arterial pressures were made with known pressures of 20 and $40 \mathrm{cmH}_{2} \mathrm{O}$ and venous pressures were made with known pressures of 5 and $15 \mathrm{cmH}_{2} \mathrm{O}$. Calibration of the force transducer was performed by adding $1 \mathrm{ml}$ increments of water $(1 \mathrm{~g})$ to the platform at the beginning of each data sequence due to small changes in placement of the force transducer above the platform affecting the calibration. The force transducer in conjunction with the first class lever apparatus showed a linear calibration for effective masses between 0 and $10 \mathrm{ml}$ of water, the range within which all subsequent measurements were made.

Once the preparation was stabilized, data collection was begun. During perfusion, the outflow cannula was raised or lowered vertically by a known distance using the venous outflow pressure regulator. An increase or decrease in the height of the top of the VO cannula effectively raised or lowered the pressure against the circulatory system by that distance using pressure units of $\mathrm{cmH}_{2} \mathrm{O}$. Pressure increments of one to four $\mathrm{cmH}_{2} \mathrm{O}$ were used, with two and three being the most common. The mass of the preparation was constantly monitored over time. In a stable situation, any increase in the mass of the preparation was interpreted as the rate of whole body systemic transcapillary filtration calculated in units of $\mathrm{ml} \cdot \mathrm{min}^{-1} \cdot \mathrm{kg}$ body mass ${ }^{-1}$. No correction was made for the difference in specific gravity of Ringers and water, although water was used for the calibration. Any increase or decrease in pressure against the vasculature resulted in an increase or 
decrease respectively, in the rate of filtration. Data were normally collected in intervals of $1000 \mathrm{~s}$, during which time up to 20 changes were made in $\mathrm{P}_{\mathrm{v}}$. Most preparations were used for 3-4 of these data collection intervals, resulting in up to 70 data points per preparation. At the end of the experiments, animals were pithed. Superscope waves were then converted to the proper units according to the calibration, transferred to Igor Pro (WaveMetrics, Inc., v 3.03) where data were analyzed. Best fit lines were applied to the trace of the mass change with time to yield filtration rates both before and after any change in the venous outflow pressure. Changes in the pressure were not induced until the filtration rate was stable and measurements of the resulting new filtration rates were taken only after the new filtration rate and venous pressure had stabilized, which was normally within 5-10 seconds. Average arterial and venous pressures were recorded for the same interval of time during which the filtration rate was analyzed. Care was taken to ensure that the venous pressure had stabilized during this time interval. Figure 3 shows a typical trace with both an increase and decrease in height of the VO cannula and the typical venous and arterial trace.

Immediately after a change in pressure was induced, the compliance of the vasculature often produced an immediate increase (when pressure was increased) or decrease (when pressure was reduced) in the mass of the animal, but would then stabilize and reequilibrate at a new venous pressure and linear filtration rate. Due to the compliance of the vasculature, the actual change in venous pressure was lower 
than the induced pressure change at the VO. The compliance curve was highly variable in form and magnitude, due to the relatively high changes in filtration rate of the system (see Discussion), the vascular compliance was masked by an immediate increase in the rate of filtration, showed considerable individual variation, and was not analyzed. The linearity of the resulting filtration rate was demonstrated by extremely tight best fit lines with $r$ values normally greater than 0.95 . The majority of the readings yielded $\mathrm{r}$ values greater than 0.99 .

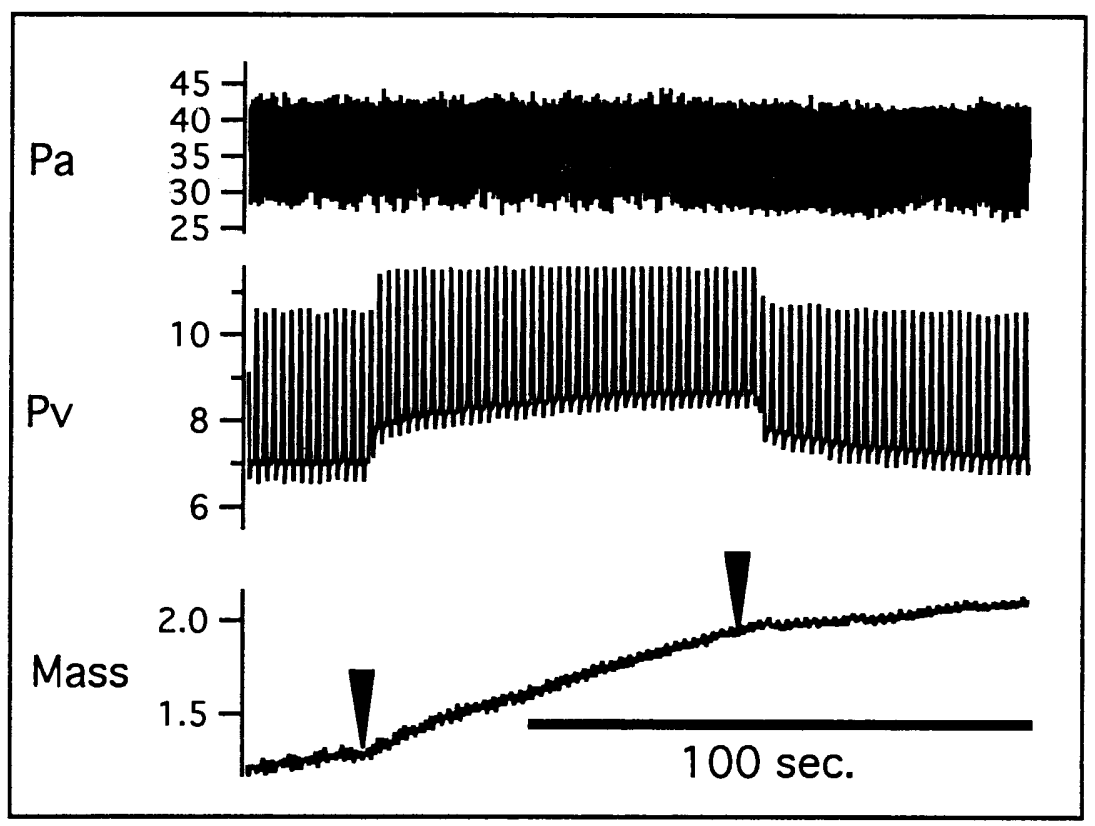

Figure 3. Demonstration of typical traces as obtained during acquisition of in vitro preparation representing $\mathrm{P}_{\mathrm{a}}(\mathrm{mmHg}), \mathrm{P}_{\mathrm{v}}(\mathrm{mmHg})$ and Mass $(\mathrm{g})$. Arrows represent vertical displacement of the venous outflow cannula. Note different scale for $P_{a}$ and $P_{v}$. 
Whole body capillary filtration coefficients were calculated by the change in filtration rate per the change in pressure at the capillary level per kilogram animal $\left(\mathrm{ml} \cdot \mathrm{min}^{-1} \cdot \mathrm{kg}^{-1} \cdot \mathrm{mmH}^{-1}\right)$. This necessitates a measurement of capillary pressure which is not directly measured in this experimental design. While venous pressure has been used as an estimate of capillary pressure in certain studies (Hillman et al., 1987), Pappenheimer and Soto-Rivera (1948) developed a method of estimating the capillary pressure by measuring the relative pre- and post-capillary resistances. The pre-capillary resistance accounts for the drop in pressure from the heart (arterial pressure) to the capillary bed divided by the flow. The post-capillary resistance is determined by the drop in pressure from the capillary bed to the vena cava (venous pressure) and may be stated as

$$
r_{v}=\left(P_{c}-P_{v}\right) / Q_{s y s}
$$

These were measured in two toads. At the beginning of each of these preparations, isovolumetry (or isogravimetry) was achieved for a given $\mathrm{P}_{\mathrm{a}}$ and flow $\left(\mathrm{Q}_{\text {sys }}\right)$ by adjusting the VO cannula to a height such that zero net filtration occurred (i.e., no change in mass of the animal over time) thus establishing the first triplet of isovolumetric venous pressure $\left(\mathrm{P}_{\mathrm{vi}}\right)$ and isovolumetric arterial pressure $\left(\mathrm{P}_{\mathrm{ai}}\right)$ for a given isovolumetric flow $\left(\mathrm{Q}_{\text {sysi }}\right)$. The flow was then changed, resulting in a new arterial pressure for which the venous pressure was again adjusted to reestablish 
isovolumetry, resulting in a second triplet, etc. Any number of isovolumetric states can be induced with a unique triplet for each.

The points were then plotted (Figure 4) with $\mathrm{Q}_{\text {sysi }}$ on the $\mathrm{X}$ axis and $\mathrm{P}_{\mathrm{ai}}$ or $\mathrm{P}_{\mathrm{vi}}$ on the $\mathrm{Y}$-Axis. The line drawn through $\mathrm{P}_{\mathrm{vi}}$ was then extrapolated to the $\mathrm{Y}$ axis where flow would equal zero to estimate the isovolumetric capillary pressure. This is equivalent to a state where $P_{a i}=P_{v i}$ and both would equal $P_{c i}$ a situation unattainable in an experimental context. Equation 4 still holds true in the isovolumetric state, and rearranging the equation yields

$$
P_{c i}=Q_{s y s i} r_{v}+P_{v i}
$$

Equation 5 shows that at zero flow $\left(\mathrm{Q}_{\text {sysi }}=0\right), \mathrm{P}_{\mathrm{ci}}=\mathrm{P}_{\mathrm{vi}}$. Thus, the $\mathrm{Y}$-intercept is equal to the isovolumetric capillary pressure of the preparation. The line drawn through $\mathrm{P}_{\mathrm{ai}}$ may also be used to derive $\mathrm{P}_{\mathrm{ci}}$, but because the slope of the arterial line is greater than the venous line and the venous pressure better approximates the capillary pressure, a greater error is introduced if the arterial slope is used to estimate $\mathrm{P}_{\mathrm{ci}}$.

The absolute value of the slope of the line through $\mathrm{P}_{\mathrm{vi}}$ is thus equal to equation 4 and equals the post-capillary resistance $\left(r_{v}\right)$, in units of $\mathrm{mmHg} \cdot \mathrm{min} \cdot \mathrm{ml}^{-1}$ (Pappenheimer and Soto-Rivera, 1948). The same argument holds true for the slope 
of the line drawn through $\mathrm{P}_{\mathrm{a}}$ yielding the pre-capillary resistance. This can be done with only 2 points such that

$$
r_{v}=\left[P_{v i}(a)-P_{v i}(b)\right] /\left[Q_{s y s i}(a)-Q_{\text {sysi }}(b)\right]
$$

where (a) and (b) represent two distinct isovolumetric states. A best fit line can be fit to an entire set of points for a broader range of pairs of isovolumetric pressures and the slope of such a line is equivalent to Equation 6, yielding the post-capillary resistance and of course the same principle can be applied to the pre-capillary resistance. The ratio of these pressures is used to estimate capillary pressure (Pappenheimer and Soto-Rivera, 1948) for any given venous and arterial pressure, using the formula

$$
P_{c}=\left[P_{v}+\left(r_{v} / r_{a}\right) P_{a}\right] /\left[1+\left(r_{v} / r_{a}\right)\right]
$$

\section{Hormonal Sensitivity of the System}

Histamine and epinephrine were used to test the efficacy of the system. Various investigators (see Introduction) have established that histamine increases both FR and CFC in organ and limb studies (Marciniak et al., 1978; Rippe and Grega, 1978; Grega et al., 1972, 1980,1986). One toad was used to measure CFC using normal "control" Ringers. The animal was then brought to an isovolumetric 
state and a perfusion with histamine (Sigma Chemical Co., Lot 61 H0493) at a concentration of $10 \mathrm{mg} / \mathrm{L}$ was begun. Any changes in FR were noted and CFC was again measured. Isovolumetry was reestablished, and the histamine perfusion was then increased to a concentration of $100 \mathrm{mg} / \mathrm{L}$ and subsequent measurements were again taken. Isovolumetry was again reestablished and a return to control Ringers was begun with subsequent measurements being taken.

Frog Atrial Natriuretic Peptide (fANP) was obtained from commercial suppliers (Sigma Chemical: Fragment 4-24, frog, synthetic, MW=2272.6, 81\% purity). $0.1 \mathrm{mg}$ was dissolved in hormone solvent (Sigma Chemical: $3 \mathrm{mg}$ phenol and $50 \mathrm{mg}$ glucose per $\mathrm{ml} \mathrm{H}_{2} \mathrm{O}$ ) which was then added to Ringers solution to obtain $0.1 \mathrm{nM}$ and $1.0 \mathrm{nM}$ solutions.

Three frogs and two toads were perfused with Ringers solutions with fANP. An initial control trace was obtained, then perfusion was begun with the lower concentration of fANP for an entire trace $(1000 \mathrm{sec})$. A third trace was taken while perfusing at the higher concentration of fANP. The preparation was returned to control Ringers for a final trace after which experimentation was terminated. Previous control animals showed no significant change in CFC over time (see Results), so it was determined that a control value should be obtained for individual animals before perfusion with fANP. During all infusions, CFC was obtained exactly as in control conditions as outlined above. 
Data were transcribed to Excel (Microsoft Corporation, v. 5.0) for storage and subsequent calculations. Statistics were performed both in Excel and Statistica (Statsoft, Inc., v. 3.0b). Graphical representations were generated from Igor, Statistica and CA - Cricket Graph III (Computer Associates International, Inc., v. 1.5.2)

Data are presented as means \pm SE unless otherwise indicated. All values represent systemic circulation values only, and the mass of the animal was not corrected for pulmonary tissue weight. 


\section{RESULTS}

\section{Isovolumetric Capillary Pressure and Pre- and Post-Capillary Resistance}

A best-fit linear regression was applied to the isovolumetric arterial pressures, venous pressures and systemic flows for two toads to establish the relative pre- and post-capillary resistances (Pappenheimer and Soto-Rivera, 1948) as well as isovolumetric capillary pressure (Table 1, Figure 4). From this regression, pre-capillary resistance $\left(\mathrm{r}_{\mathrm{a}}\right)$ was $1.81 \pm 0.19 \mathrm{mmHg} \cdot \mathrm{min} \cdot \mathrm{ml}^{-1}(\mathrm{p}<0.001$; $\left.\mathrm{r}^{2}=0.918\right)$. Post-capillary resistance $\left(\mathrm{r}_{\mathrm{v}}\right)$ was $0.32 \pm 0.14 \mathrm{mmHg} \cdot \mathrm{min} \cdot \mathrm{ml}^{-1}(\mathrm{p}<0.05$; $r^{2}=0.408$. Isovolumetric capillary pressure $\left(\mathrm{P}_{\mathrm{ci}}\right)$ determined from the $\mathrm{Y}$-intercept of the venous resistance line was $7.2 \pm 1.6 \mathrm{mmHg}\left(\mathrm{p}<0.005 ; \mathrm{r}^{2}=0.408\right)$. The $95 \%$ confidence limits on $\mathrm{P}_{\mathrm{ci}}$ were $[3.48,10.98 \mathrm{mmHg}]$. The same line for $\mathrm{P}_{\mathrm{ai}}$ predicts an isovolumetric capillary pressure $\left(\mathrm{P}_{\mathrm{ci}}\right)$ of $1.3 \pm 2.3 \mathrm{mmHg}\left(\mathrm{p}<0.001 ; \mathrm{r}^{2}=0.918\right)$. The 95\% confidence limits on this value of $P_{c i}$ were $[-3.9,6.5]$.

As an alternative to the method of least-squares linear regression through all points, data were analyzed in terms of the difference between consecutive points on a single animal (Table 1). This yielded a slightly higher post-capillary resistance $\left(0.32\right.$ versus $\left.0.37 \mathrm{mmHg} \cdot \mathrm{min} \cdot \mathrm{ml}^{-1}\right)$ on average, which increases the overall resistance of the combined terms. The pre-capillary resistance was only slightly different $\left(1.80\right.$ versus $\left.1.81 \mathrm{mmHg} \cdot \mathrm{min} \cdot \mathrm{ml}^{-1}\right)$. The ratio of post- to pre-capillary 


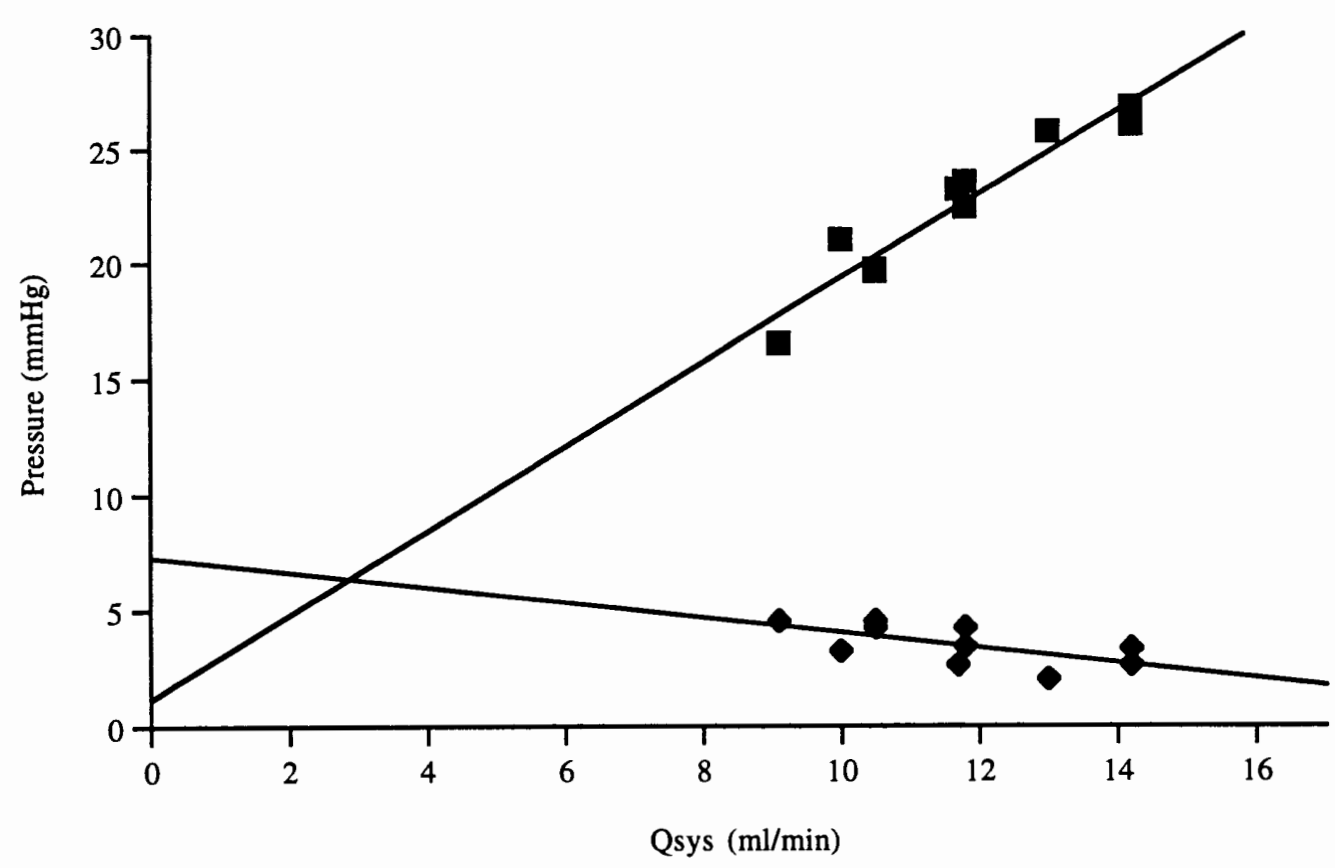

$\overline{\text { Figure 4. Isovolumetric pressures plotted by Qsys, } P_{\mathrm{ai}} \text { and } \mathrm{P}_{\mathrm{vi}} \text {. for two toads (Bufo marinus). }}$ Lines are least squares best fit lines representing $r_{v}$ (diamonds) $=0.32 \pm 0.14$ $\mathrm{mmHg} \cdot \min \cdot \mathrm{ml}^{-1}\left(p<0.05 ; r^{2}=0.408\right)$ and $r_{v}$ (squares) $=1.81 \pm 0.19 \mathrm{mmHg} \cdot \mathrm{min} \cdot \mathrm{ml}^{-1}$ $\left(p<0.001 ; r^{2}=0.918\right)$. The line through $P_{v i}$ (diamonds) is extrapolated back such that the $Y$ intercept represents isovolumetric capillary pressure $\left(P_{c i}\right)=7.2 \pm 1.6 \mathrm{mmHg}(p<0.001$; $\left.r^{2}=0.408\right)$. The same line for $P_{a i}$ predicts an isovolumetric capillary pressure $\left(P_{c i}\right)=1.3 \pm$ $2.3 \mathrm{mmHg}\left(p<0.001 ; r^{2}=0.918\right)$.

resistance would then be 0.20 , slightly higher than the previous method. This method also yielded a slightly higher isovolumetric capillary pressure, $7.8 \pm 0.5$ mmHg.

The estimates of pre- and post-capillary resistance $\left(\mathrm{r}_{\text {tot }}\right)$ should sum to yield the systemic resistance $\left(\mathrm{r}_{\mathrm{sys}}\right)$, as calculated for each animal from their respective 
Table 1. Isovolumetric data set for two toads (Bufo marinus). Each row represents a unique isovolumetric state where the filtration rate was zero. $Q_{\text {sys }}\left(\mathrm{ml} \cdot \mathrm{min}^{-1}\right) ; P_{\mathrm{ai}}$, $P_{v i}, P_{c i}\left(m l \cdot m^{-1}\right) ; r_{a}, r_{v}, r_{\text {tot }}, r_{v} / r_{a}, r_{\text {tot }}, r_{\text {sys }}(m m H g l \cdot m i n \cdot m l) ; r_{\text {tot }} / r_{\text {sys }}$ (unitless ratio).

Each slope is derived from two simultaneous points in the same animal.

\begin{tabular}{|c|c|c|c|c|c|c|c|c|c|c|c|}
\hline$\overline{\text { Toad }}$ & $Q_{\text {sys }}$ & $\overline{P_{a i}}$ & $\mathrm{P}_{\mathrm{vi}}$ & $\mathrm{P}_{\mathrm{ci}}-\mathrm{a}$ & $\mathrm{P}_{\mathrm{ci}-\mathrm{V}}$ & $r_{a}$ & $r_{v}$ & $r_{\text {tot }}$ & $r_{v} / r_{a}$ & $r_{\text {sys }}$ & $r_{\text {sys }} / r_{\text {tot }}$ \\
\hline 6 & 10.0 & 21.0 & 3.2 & & & & & & & 1.77 & \\
\hline 6 & 11.7 & 23.2 & 2.6 & 8.0 & 7.1 & 1.30 & 0.39 & 1.69 & 0.30 & 1.76 & 1.04 \\
\hline 6 & 13.0 & 25.7 & 2.0 & 0.7 & 7.9 & 1.92 & 0.45 & 2.37 & 0.23 & 1.82 & 0.77 \\
\hline 7 & 10.5 & 19.6 & 4.2 & & & & & & & 1.47 & \\
\hline 7 & 11.8 & 22.4 & 3.4 & -2.3 & 10.7 & 2.09 & 0.62 & 2.71 & 0.30 & 1.61 & 0.59 \\
\hline 7 & 14.2 & 26.0 & 2.6 & 4.6 & 7.0 & 1.50 & 0.31 & 1.81 & 0.21 & 1.64 & 0.91 \\
\hline 7 & 9.1 & 16.5 & 4.5 & -0.2 & 7.8 & 1.85 & 0.36 & 2.21 & 0.20 & 1.33 & 0.60 \\
\hline 7 & 11.8 & 23.5 & 4.2 & -6.8 & 5.5 & 2.56 & 0.11 & 2.67 & 0.04 & 1.63 & 0.61 \\
\hline 7 & 14.2 & 26.8 & 3.3 & 7.2 & 8.5 & 1.38 & 0.37 & 1.75 & 0.27 & 1.65 & 0.94 \\
\hline 7 & 10.5 & 19.7 & 4.5 & -0.3 & 7.8 & 1.91 & 0.32 & 2.23 & 0.17 & 1.45 & 0.65 \\
\hline \multicolumn{4}{|c|}{ Average of individuals: } & 1.3 & 7.8 & 1.81 & 0.37 & 2.18 & 0.20 & 1.61 & 0.74 \\
\hline \multicolumn{4}{|c|}{ Least Squares Method: } & 1.3 & 7.3 & 1.80 & 0.32 & 2.12 & 0.18 & 1.61 & 0.76 \\
\hline
\end{tabular}

arterial, venous and pump flow at the time of each isovolumetric measurement. As can be seen in Table 2, the Pappenheimer and Soto-Rivera method underestimated systemic resistance by an average of $26 \%$ when individual measurements are averaged, and by $24 \%$ using the least-squares linear fit estimate.

The estimate of capillary pressure at any time is highly dependent on the ratio of pre- to post-capillary resistance, this ratio was determined by the least-squares linear fit method to be 0.18 . Capillary pressure is determined from the formula $P_{c}=\left[P_{v}+\left(r_{v} / r_{a}\right) P_{a}\right] /\left[1+\left(r_{v} / r_{a}\right)\right]$, from which all CFC measures were estimated (Pappenheimer and Soto-Rivera, 1948). 


\section{Histamine and Epinephrine}

One toad was used to determine the efficacy of the preparation using a well established method of increasing or decreasing capillary filtration and/or CFC, using histamine perfusion (Figure 5).

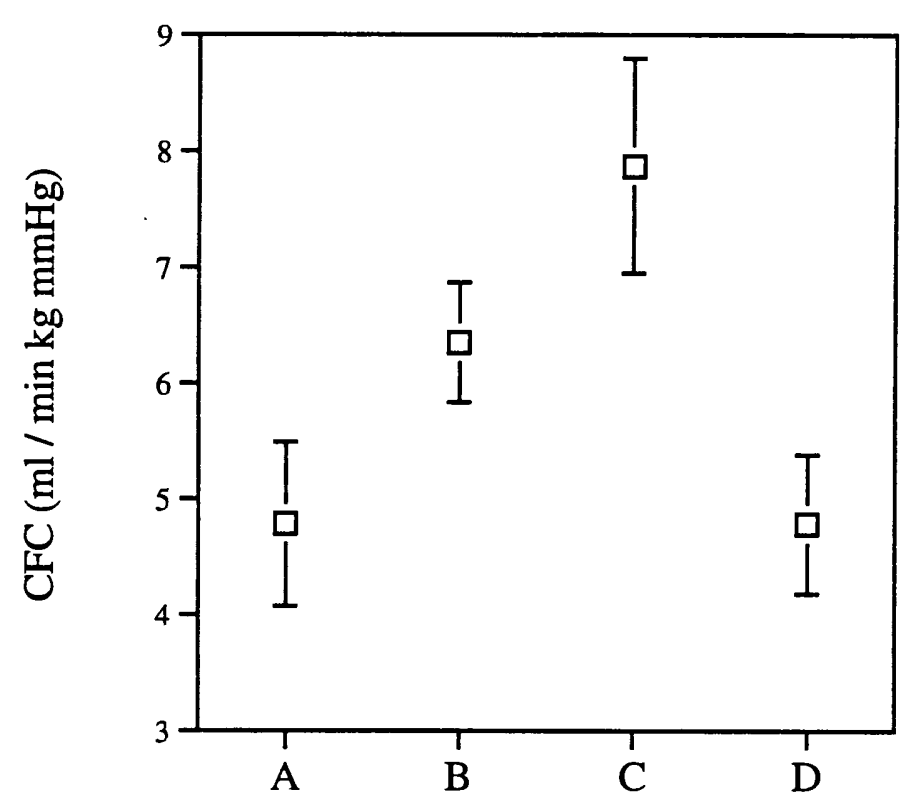

Figure 5. Comparison of $\mathrm{CFC}_{\mathrm{a}}$ for one toad (Bufo marinus) during: $\mathrm{A}$. control Ringers perfusion; B. histamine treatment (10 mg/L); C. histamine treatment (100 mg/L); D. return to control Ringers.

Control CFC was $4.78 \pm 0.71 \mathrm{ml} \cdot \mathrm{min}^{-1} \cdot \mathrm{kg}^{-1} \cdot \mathrm{mmHg}^{-1}$ (four replicates). Filtration rate increased from approximately zero (isovolumetric) to 2.35 $\mathrm{ml} \cdot \mathrm{min}^{-1} \cdot \mathrm{kg}^{-1}$ within 1 minute of histamine $(10 \mathrm{mg} / \mathrm{L})$ reaching the system. CFC had increased to $6.35 \pm 0.52 \mathrm{ml} \cdot \mathrm{min}^{-1} \cdot \mathrm{kg}^{-1} \cdot \mathrm{mmHg}^{-1}$. 
Perfusion was then begun with an even stronger dose of histamine (100 $\mathrm{mg} / \mathrm{L}$ ) after the venous outflow pressure was adjusted to a new isovolumetric state and FR again increased from approximately zero (isovolumetric) to 1.25 $\mathrm{ml} \cdot \mathrm{min}^{-1} \cdot \mathrm{kg}^{-1}$ within 2 minutes of the increased dosage reaching the system. CFC increased to $7.87 \pm 0.92 \mathrm{ml} \cdot \mathrm{min}^{-1} \cdot \mathrm{kg}^{-1} \cdot \mathrm{mmHg}^{-1}$.

Perfusion was then begun with a mixture of histamine $(10 \mathrm{mg} / \mathrm{L})$ and epinephrine $\left(2 \times 10^{-6} \mathrm{M}\right)$ after the venous outflow pressure was adjusted to a new isovolumetric state. Although the FR did not change significantly (initial increase and return to isovolumetry within $2-3$ minutes), CFC decreased to $4.78 \pm 0.60$ $\mathrm{ml} \cdot \mathrm{min}^{-1} \cdot \mathrm{kg}^{-1} \cdot \mathrm{mmHg}^{-1}$.

ANOVA revealed significant differences (all $\mathrm{p}<0.05)$ between: the control group and the higher dosage of histamine; the control group and the combined histamine groups; and the higher histamine dosage and the histamine plus epinephrine group. The control group and the histamine plus epinephrine group were not significantly different.

\section{Capillary Filtration Coefficient}

The average CFC during perfusion of control Ringers for each toad and frog was $6.68 \pm 0.51$ and $5.07 \pm 0.23 \mathrm{ml} \cdot \mathrm{min}^{-1} \cdot \mathrm{kg}^{-1} \cdot \mathrm{mmHg}^{-1}$, respectively (Figure $6 \mathrm{~b}$ ). The average of all measurements was slightly different owing to the variation in 
Table 2. Control measurements on individual Bufo marinus and Rana catesbeiana, including averages of individuals and averages of all $n$ measurements. Columns indicate Animal Number, Sex, $n=$ number of control measurements, mass $(\mathrm{kg}), \mathrm{CFC}_{\mathrm{a}}$ $\left(\mathrm{ml} \cdot \mathrm{min}^{-1} \cdot \mathrm{kg}^{-1} \cdot \mathrm{mmHg}^{-1}\right), C_{\text {res }}$ (unitless ratio), $r_{\text {sys }}\left(\mathrm{mmHg} \cdot \mathrm{min} \cdot \mathrm{ml}^{-1} \cdot \mathrm{kg}^{-1}\right), P_{\mathrm{v}}(\mathrm{mmHg}), \mathrm{P}_{\mathrm{a}}$ $(\mathrm{mmHg}), \mathrm{P}_{\mathrm{c}}(\mathrm{mmHg}), \mathrm{CFC}_{\mathrm{b}}\left(\mathrm{ml} \cdot \mathrm{min}^{-1} \cdot \mathrm{kg}^{-1} \cdot \mathrm{mmHg}^{-1}\right)$ and $\mathrm{P}_{\mathrm{a}}(\mathrm{mmHg})$. Values indicated are means \pm SE.

\section{Bufo marinus}

$\begin{array}{llllllllllll}\text { Toad Sex } & \text { Mass } n & C_{F} & \mathbf{C F}_{\mathrm{a}} & \mathrm{C}_{\mathrm{res}} & \mathbf{r}_{\text {sys }} & \mathbf{P}_{\mathrm{v}} & \mathbf{P}_{\mathrm{a}} & \mathbf{P}_{\mathrm{c}} & \mathbf{C F C}_{\mathrm{b}} & \mathbf{P}_{\mathrm{ci}}\end{array}$

\begin{tabular}{|c|c|c|c|c|c|c|c|c|c|c|c|}
\hline 1 & Male & 0.216 & 17 & $\begin{array}{l}7.50 \\
\pm 0.55\end{array}$ & 0.64 & $\begin{array}{l}0.329 \\
\pm 0.005\end{array}$ & $\begin{array}{c}6.0 \\
\pm 0.1\end{array}$ & $\begin{array}{l}20.8 \\
\pm 0.3\end{array}$ & $\begin{array}{c}8.2 \\
\pm 0.2\end{array}$ & $\begin{array}{c}6.67 \\
r^{2}=0.71\end{array}$ & $\begin{array}{c}6.82 \\
r^{2}=0.71\end{array}$ \\
\hline 2 & Male & 0.185 & 17 & $\begin{array}{c}8.10 \\
\pm 1.04\end{array}$ & 0.67 & $\begin{array}{c}0.433 \\
\pm 0.003\end{array}$ & $\begin{array}{c}6.0 \\
\pm 0.1\end{array}$ & $\begin{array}{l}23.6 \\
\pm 0.5\end{array}$ & $\begin{array}{l}8.7 \\
\pm 0.1\end{array}$ & $\begin{array}{c}6.99 \\
r^{\prime}=0.48\end{array}$ & $\begin{array}{c}7.57 \\
\dot{r}=0.48\end{array}$ \\
\hline 3 & Male & 0.220 & 24 & $\begin{array}{c}6.38 \\
\pm 0.61\end{array}$ & 0.65 & $\begin{array}{c}0.416 \\
\pm 0.002\end{array}$ & $\begin{array}{c}6.3 \\
\pm 0.2\end{array}$ & $\begin{array}{l}27.5 \\
\pm 0.2\end{array}$ & $\begin{array}{c}9.5 \\
\pm 0.2\end{array}$ & $\begin{array}{c}5.75 \\
\dot{r}^{\prime}=0.29\end{array}$ & $\begin{array}{c}8.31 \\
r^{2}=0.29\end{array}$ \\
\hline 4 & Male & 0.239 & 13 & $\begin{array}{c}5.19 \\
\pm 0.45\end{array}$ & 0.72 & $\begin{array}{l}0.480 \\
\pm 0.005\end{array}$ & $\begin{array}{c}6.6 \\
\pm 0.2\end{array}$ & $\begin{array}{l}24.7 \\
\pm 0.1\end{array}$ & $\begin{array}{c}9.3 \\
\pm 0.2\end{array}$ & $\begin{array}{c}4.81 \\
r^{2}=0.68\end{array}$ & $\begin{array}{c}8 \\
r^{2}=0.68\end{array}$ \\
\hline \multirow[t]{3}{*}{5} & Male & 0.293 & 15 & $\begin{array}{r}6.21 \\
0.64 \\
\end{array}$ & 0.64 & $\begin{array}{c}0.534 \\
\pm 0.003 \\
\end{array}$ & $\begin{array}{r}5.9 \\
\pm 0.2 \\
\end{array}$ & $\begin{array}{r}20.9 \\
\pm 0.1 \\
\end{array}$ & $\begin{array}{c}8.2 \\
\pm 0.1 \\
\end{array}$ & $\begin{array}{c}5.52 \\
\dot{r}^{\prime}=0.73 \\
\end{array}$ & $\begin{array}{c}6.94 \\
\dot{r}^{2}=0.73 \\
\end{array}$ \\
\hline & Average: & $\begin{array}{r}0.259 \\
\pm 0.022\end{array}$ & & $\begin{array}{c}6.68 \\
\pm 0.51\end{array}$ & 0.66 & $\begin{array}{l}0.438 \\
\pm 0.034\end{array}$ & $\begin{array}{c}6.2 \\
\pm 0.1\end{array}$ & $\begin{array}{l}23.5 \\
\pm 01.2\end{array}$ & $\begin{array}{c}8.8 \\
\pm 0.3\end{array}$ & $\begin{array}{c}5.95 \\
\pm 0.40\end{array}$ & $\begin{array}{r}7.53 \\
\pm 0.29\end{array}$ \\
\hline & & Avg. of & $\ln$ & $\begin{array}{l}6.73 \\
\pm 0.33\end{array}$ & & $\begin{array}{c}0.432 \\
\pm 0.006\end{array}$ & $\begin{array}{r}6.0 \\
\pm 0.1\end{array}$ & $\begin{array}{l}23.8 \\
\pm 0.3\end{array}$ & $\begin{array}{c}8.8 \\
\pm 0.1\end{array}$ & & \\
\hline
\end{tabular}

Rana catesbeiana

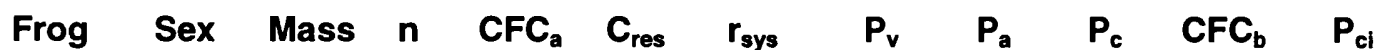

\begin{tabular}{|c|c|c|c|c|c|c|c|c|c|c|c|}
\hline 1 & Female & 0.364 & 26 & $\begin{array}{c}4.43 \\
\pm 0.25\end{array}$ & 0.65 & $\begin{array}{l}0.629 \\
\pm 0.006\end{array}$ & $\begin{array}{c}4.5 \\
\pm 0.1\end{array}$ & $\begin{array}{l}23.8 \\
\pm 0.3\end{array}$ & $\begin{array}{l}7.4 \\
\pm 0.1\end{array}$ & $\begin{array}{c}4.69 \\
r^{\prime}=0.79\end{array}$ & $\begin{array}{c}4.64 \\
r^{\prime}=0.79\end{array}$ \\
\hline 2 & Male & 0.358 & 37 & $\begin{array}{l}5.05 \\
\pm 0.33\end{array}$ & 0.54 & $\begin{array}{c}0.654 \\
\pm 0.006\end{array}$ & $\begin{array}{c}6.3 \\
\pm 0.1\end{array}$ & $\begin{array}{l}21.6 \\
\pm 0.2\end{array}$ & $\begin{array}{c}8.6 \\
\pm 0.1\end{array}$ & $\begin{array}{c}4.72 \\
\dot{r}=0.71\end{array}$ & $\begin{array}{l}6.78 \\
\dot{r}=0.71\end{array}$ \\
\hline 4 & Female & 0.610 & 10 & $\begin{array}{l}5.47 \\
\pm 0.34\end{array}$ & 0.49 & $\begin{array}{l}0.831 \\
\pm 0.007\end{array}$ & $\begin{array}{c}6.5 \\
\pm 0.1\end{array}$ & $\begin{array}{l}21.7 \\
\pm 0.03\end{array}$ & $\begin{array}{c}8.8 \\
\pm 0.1\end{array}$ & $\begin{array}{c}5.15 \\
r=0.64\end{array}$ & $\begin{array}{l}7.94 \\
r^{\prime}=0.64\end{array}$ \\
\hline 5 & Male & 0.721 & 9 & $\begin{array}{r}5.31 \\
\pm 0.31 \\
\end{array}$ & 0.39 & $\begin{array}{r}1.040 \\
\pm 0.007 \\
\end{array}$ & $\begin{array}{r}3.9 \\
\pm 0.1 \\
\end{array}$ & $\begin{array}{r}20.8 \\
\pm 0.04 \\
\end{array}$ & $\begin{array}{r}6.5 \\
\pm 0.1 \\
\end{array}$ & $\begin{array}{c}5.43 \\
r^{\prime}=0.59 \\
\end{array}$ & $\begin{array}{c}6.01 \\
r^{\prime}=0.59 \\
\end{array}$ \\
\hline & Averag & $\begin{array}{c}0.473 \\
\pm 0.081\end{array}$ & & $\begin{array}{c}5.07 \\
\pm 0.23\end{array}$ & 0.52 & $\begin{array}{l}0.789 \\
\pm 0.095\end{array}$ & $\begin{array}{l}5.27 \\
\pm 0.65\end{array}$ & $\begin{array}{l}22.0 \\
\pm 0.6\end{array}$ & $\begin{array}{r}7.8 \\
\pm 0.6\end{array}$ & $\begin{array}{r}5.00 \\
\pm 0.18\end{array}$ & $\begin{array}{r}6.34 \\
\pm 0.69\end{array}$ \\
\hline & & \multicolumn{2}{|c|}{ Avg. of all $n:$} & $\begin{array}{c}4.93 \\
\pm 0.18\end{array}$ & & $\begin{array}{l}0.709 \\
\pm 0.013\end{array}$ & $\begin{array}{l}5.42 \\
\pm 0.11\end{array}$ & $\begin{array}{l}22.3 \\
\pm 0.2\end{array}$ & $\begin{array}{l}8.0 \\
\pm 0.1\end{array}$ & & \\
\hline
\end{tabular}


individual determinations for each animal, which varied from 9 to 37 individual control measurements per animal. 86 control measurements were made on toads $(n=5)$ and 82 were made on frogs $(n=4)$. Means of individual animals and as a whole are presented in Table 2, (Column $\mathrm{CFC}_{\mathrm{a}}$ ) and individual means are plotted in Figure 6a.

These estimates were shown to be significantly different as a whole, not accounting for inter-animal variation ( $\mathrm{t}$-test; $\mathrm{p}<0.001$ ). An ANOVA run on toads
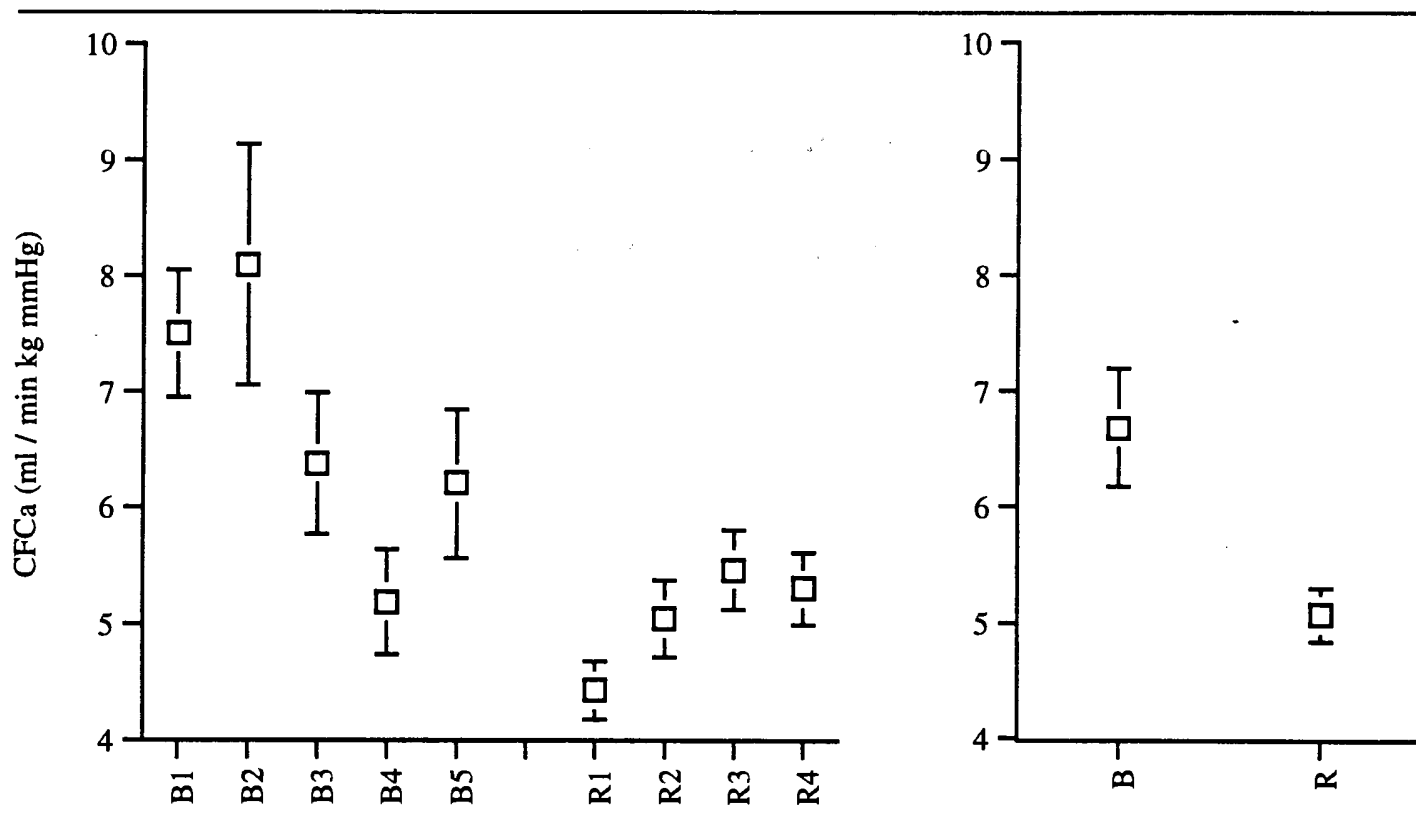

a.

Animal

b.

Species

Figure 6. $\mathrm{B}=$ (Bufo marinus) and $\mathrm{R}=\left(\right.$ Rana catesbeiana). . a. Comparison of $\mathrm{CFC}_{\mathrm{a}}$ for individual animals during control Ringers perfusion.. Comparison of $\mathrm{CFC}_{\mathrm{a}}$ for the average of all individual animals during control Ringers perfusion. All Values are means $\pm S E$ (error bars). 
and frogs separately demonstrated that there was no significant variation between animals within each species. A t-test run between the average of each species yielded arsignificant interspecific difference $(\mathrm{p}<0.05)$.

\section{Alternative Method of Calculating CFC and Isovolumetric Capillary Pressure}

$\mathrm{CFC}_{b}$ values were obtained by plotting FR versus $\mathrm{P}_{c}$ and deriving a least squares linear line from each (Figure 7). Due to the variation between individuals, best-fit lines plotted against the entire range of values did not account for a significant portion of the variance in toads and especially frogs $\left(r^{2}=0.232\right.$ and $r^{2}=0.047$, respectively). The slope of this line is equivalent to $\mathrm{CFC}_{a}$ and in toads it was reasonably close $\left(7.41 \mathrm{vs.} 6.63 \mathrm{ml} \cdot \mathrm{min}^{-1} \cdot \mathrm{kg}^{-1} \cdot \mathrm{mmHg}^{-1}\right)$. Interindividual variation between frogs was quite apparent in the distribution, indicating two distinct patterns (Figure 7c) and no significant correlation overall. However, individual animal analysis of CFC in this manner yielded a very precise alternate way of estimating CFC (Figure 8), although in all but two frogs, it consistently gave lower values than $\mathrm{CFC}_{\mathrm{a}}$. Individual values are listed in Table 2 , as well as $\mathrm{r}^{2}$ values. Overall, the mean value for $\mathrm{CFC}_{b}$ was $5.69 \pm 0.34\left(\mathrm{CFC}_{\mathrm{a}}=6.37 \pm 0.44\right)$ in toads and was $5.00 \pm 0.18 \mathrm{ml} \cdot \mathrm{min}^{-1} \cdot \mathrm{kg}^{-1} \cdot \mathrm{mmHg}^{-1}\left(\mathrm{CFC}_{\mathrm{a}}=5.07 \pm 0.23\right)$ $\mathrm{ml} \cdot \mathrm{min}^{-1} \cdot \mathrm{kg}^{-1} \cdot \mathrm{mmHg}^{-1}$ in frogs. 

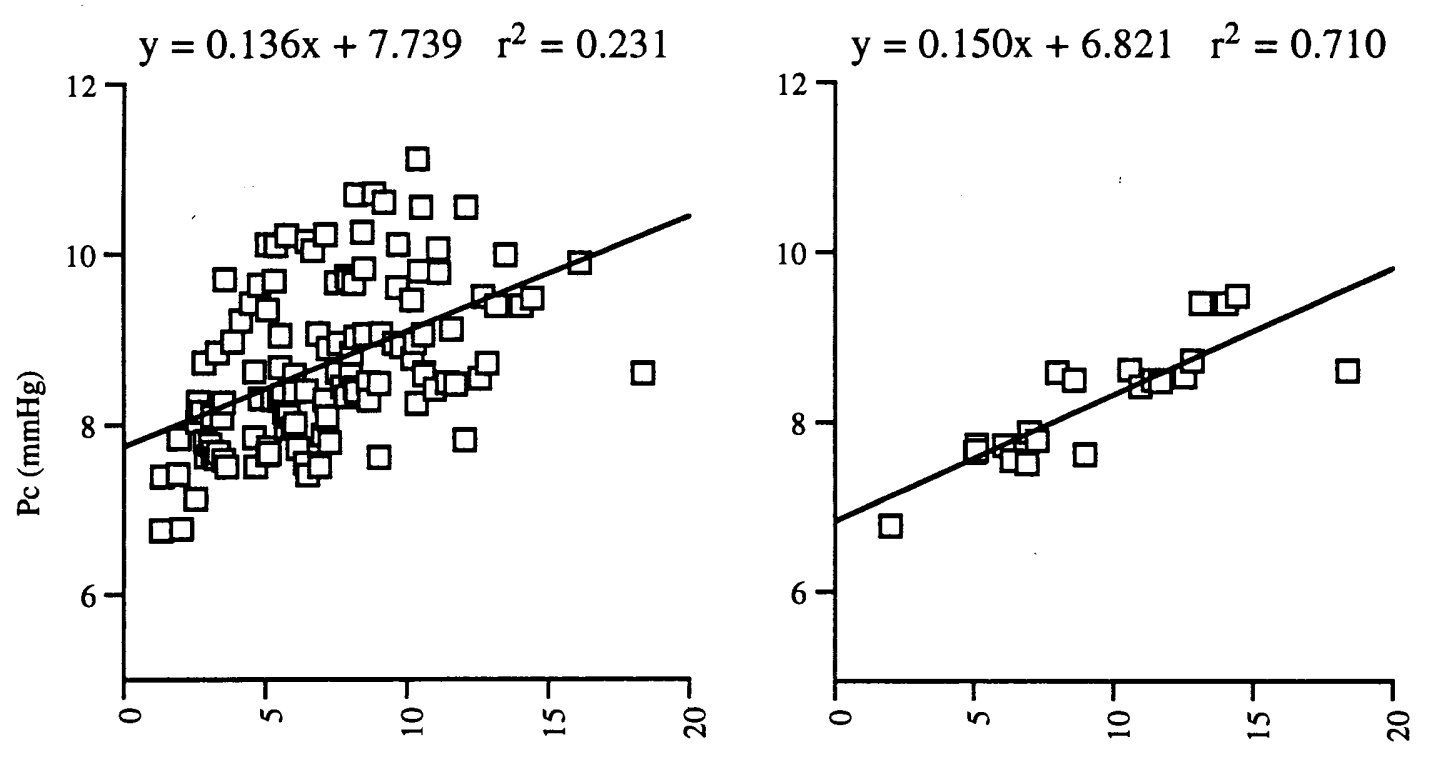

a.

b.
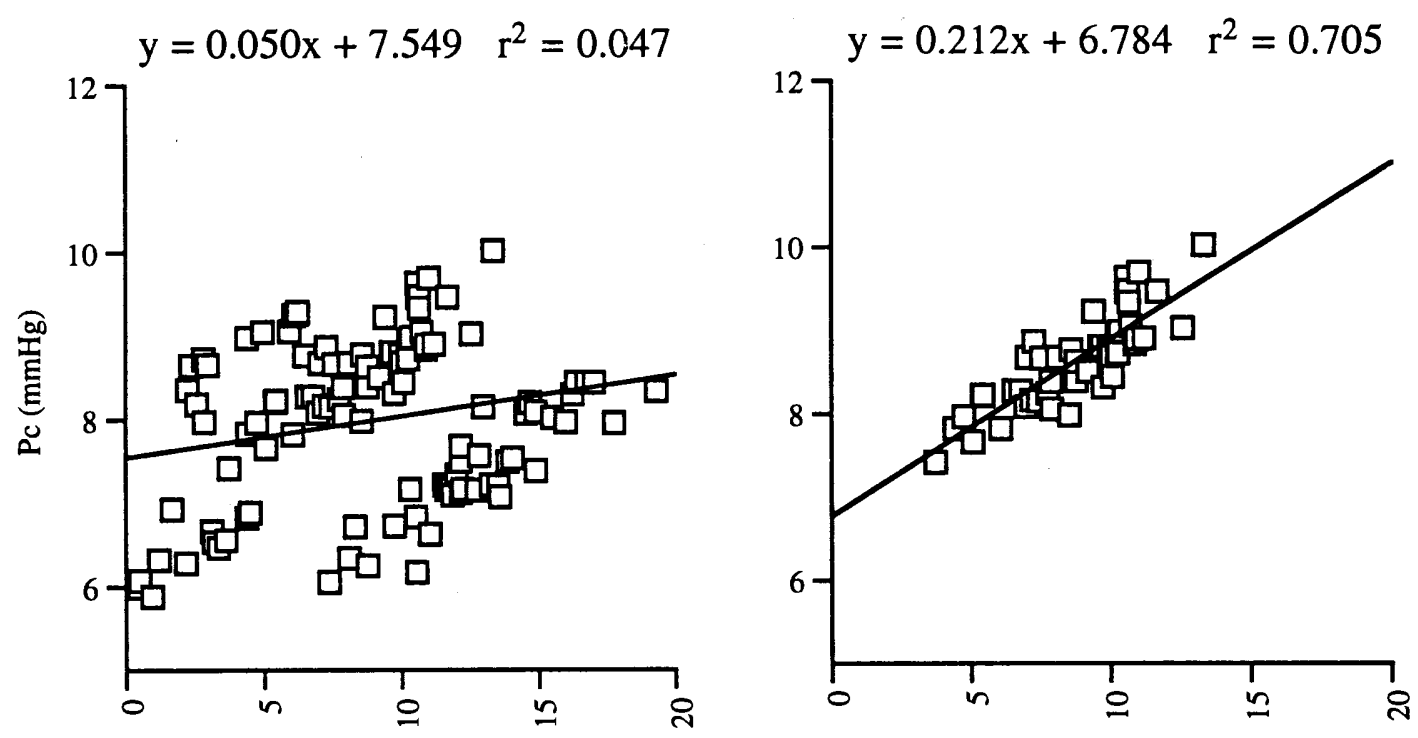

FR $(\mathrm{ml} / \mathrm{min} \mathrm{kg})$

d.

$\mathrm{FR}(\mathrm{ml} / \mathrm{min} \mathrm{kg})$

c.

Figure 7. Filtration rate $\left(\mathrm{ml} \cdot \mathrm{min}^{-1} \cdot \mathrm{kg}^{-1}\right)$ vs. capillary pressure $(\mathrm{mmHg})$ : a. for all toads (Bufo marinus); $b$. for toad number 1; c. for all frogs (Rana catesbeiana); $d$. for frog number 2. All figures indicate linear least-squares best fit lines in slope intercept form $Y=m X+b$ where $m=\mathrm{CFC}_{b}$ and $\mathrm{b}=\mathrm{P}_{\mathrm{ci}}$. 
Extrapolating the best fit line to a filtration rate of zero in this analysis yields isovolumetric capillary pressure. The mean of all toads (see Table 2) for $\mathrm{P}_{\mathrm{ci}}$ was $7.4 \pm .2 \mathrm{mmHg}$, which is consistent with the value obtained from direct isovolumetric methods of $7.2 \pm 1.6$. It was calculated to be slightly lower in frogs and more variable. Although the slope of the best fit lines in frogs was more consistent than in toads ( $\mathrm{SE}=0.17$ vs. 0.34 , respectively), the lines intercepted at highly variable points $(4.64,6.01,6.78$ and $7.94 \mathrm{mmHg}$; mean $=6.34 \pm 0.69$ $\mathrm{mmHg}$ ) and thus had highly variable and lower $\mathrm{P}_{\mathrm{ci}}$ values.

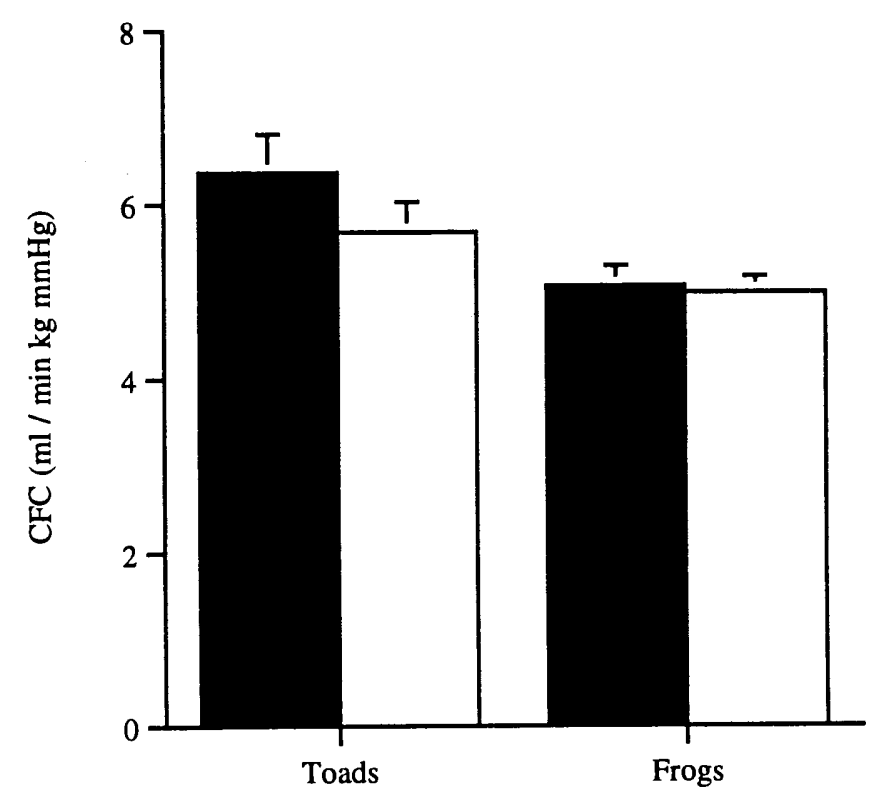

Figure 8. Comparison of average values for individual toads (Bufo marinus) and frogs (Rana catesbeiana) of $\mathrm{CFC}_{\mathrm{a}}$ (black) and $\mathrm{CFC}_{\mathrm{b}}$ (white) in units of $\mathrm{ml} \cdot \mathrm{min}^{-1} \cdot \mathrm{kg}^{-1} \cdot \mathrm{mmHg}^{-1}$. Values are means $+\mathrm{SE}$ (error bars). 


\section{Compliance vs. Mass}

Although an absolute measure of compliance cannot be measured directly from this system, the observed change in venous pressure relative to the induced change in pressure is a relative measure of compliance $\left(\mathrm{C}_{\text {rel }}\right)$ between animals. For each change in pressure induced by the venous outflow, the corresponding change in venous pressure was calculated and averaged over each animal as a ratio of

$$
\left.\mathrm{C}_{\mathrm{rel}}=\text { [change in venous pressure }\right] / \text { [induced change in pressure] }
$$

where a ratio of 1 would indicate no compliance and zero would represent infinite compliance. These data were significantly correlated to the mass of the animal $\left(\mathrm{p}<0.001 ; \mathrm{r}^{2}=0.79\right)$ when calculated over both groups (Figure 9). However some assumptions of regression were violated (uneven distribution of masses). Larger animals had a lower ratio, indicating a higher compliance of the vasculature.

\section{Resistance}

The resistance of the systemic vasculature was calculated from $\left(\mathrm{P}_{\mathrm{v}}-\mathrm{P}_{\mathrm{a}}\right) / \mathrm{Q}_{\text {sys }}$ for each individual measurement of filtration, and averaged for the entire animal (see Table 2). It was significantly negatively correlated to mass of the animals over both 


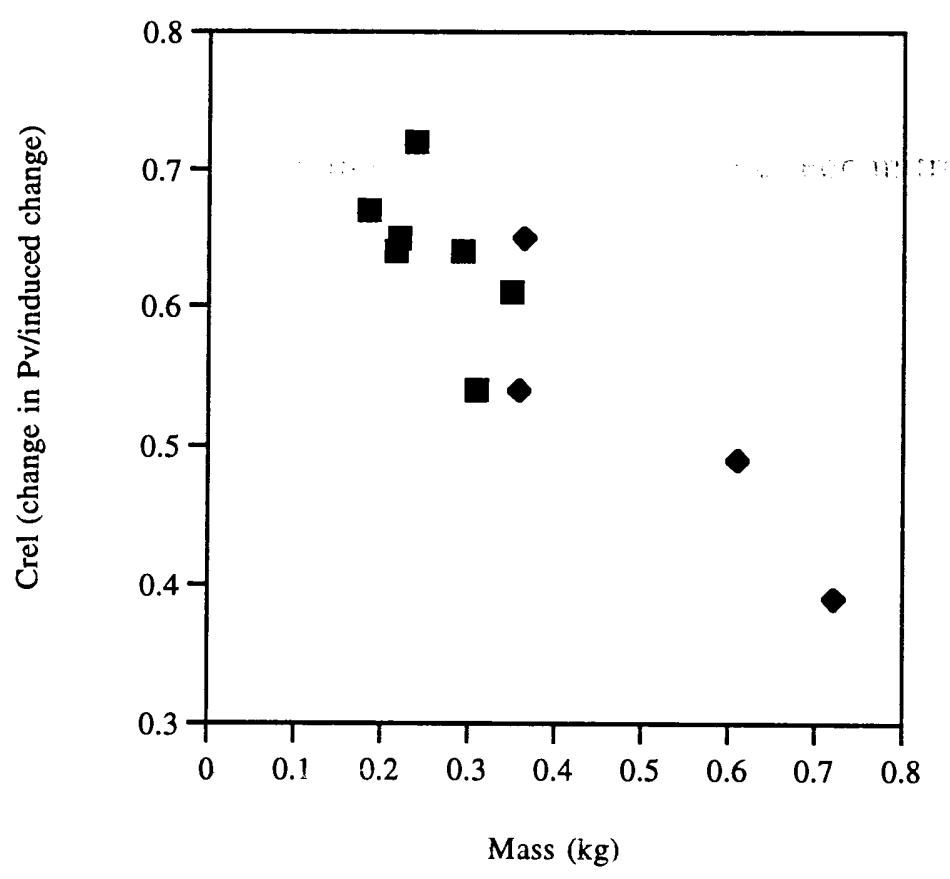

Figure 9. Depiction of the correlation between mass $(\mathrm{kg})$ and the ratio of: (average change in venous pressure) / (induced change in pressure by the venous outflow cannula). This is a relative measure of compliance of the vasculature $\left(\mathrm{C}_{\mathrm{rel}}\right)$ where a lower compliance would result in a higher ratio. Squares represent Bufo marinus and diamonds represent Rana catesbeiana.

species $\left(\mathrm{p}<0.05 ; \mathrm{r}^{2}=0.52\right)$, but was not significantly correlated within toads $\left(\mathrm{p}=0.41 ; \mathrm{r}^{2}=0.19\right)$ or within frogs $\left(\mathrm{p}=.10 ; \mathrm{r}^{2}=0.81\right)$. Again, assumption of even distribution of masses was violated for regression. No significant correlations were found for both species, although some partial correlations were found in frogs, including a negative correlation to mass independent CFC $\left(\mathrm{p}<0.01 ; \mathrm{r}^{2}=0.65\right)$, although the same trend in toads was not statistically significant. 


\section{Atrial Natriuretic Peptide}

In the first 6 animals ( 3 frogs and 3 toads), data were analyzed for a significant effect of time on "induced CFC". The order of measurements (first, second, third, etc.) was used as the general indication of time. The induced CFC was calculated from the change in the filtration rate due to adjustments to the height of the venous outflow cannula, independent of the actual change in venous and concomitant change in capillary pressure. Like the CFC estimated from the change in $\mathrm{P}_{\text {cap }}$ per change in FR, the induced CFC is expressed in $\mathrm{ml} \cdot \mathrm{min}^{-1} \cdot \mathrm{kg}^{-1} \cdot \mathrm{mmHg}^{-1}$. As capillary pressure estimates had not been made at that point, induced-CFC was regressed against order and no significant correlation was seen over time $\left(\mathrm{p}=0.397 ; \mathrm{r}^{2}=0.013\right.$ in frogs; $\left.\mathrm{p}=0.573 ; \mathrm{r}^{2}=0.05\right)$ and thus additional experiments were performed in which a series of control data were taken, followed by additional traces of perfusion with various levels of ANP (1.0 nM and $10.0 \mathrm{nM})$, followed by an additional trace of control perfusion (Table 3). The induced CFC was later demonstrated to be significantly correlated to actual CFC in both toads $\left(p<0.001 ; r^{2}=0.636\right)$ and frogs $\left(p<0.001 ; r^{2}=0.480\right)$ and by inference, no change in CFC was seen over time.

ANP had no significant effect on CFC either within individual animals, species or the group as a whole. ANOVA failed to reveal significant differences among these groups or any of the groupings mentioned. Isovolumetric capillary 
pressure was also estimated by the method discussed above. Although one of two toads showed an extremely low isovolumetric capillary during perfusion with ANP, the other toad had a high reading. The same results were seen in frogs, with a high variability above and below the mean.

\begin{tabular}{|c|c|c|c|c|}
\hline \multicolumn{5}{|c|}{$\begin{array}{l}\text { Table } 3 . \mathrm{CFC}_{\mathrm{a}} \text { values } \\
\text { control and during per } \\
\text { means } \pm \mathrm{SE} \text {. Average } \\
\text { listed for comparison. }\end{array}$} \\
\hline \multicolumn{5}{|c|}{ Bufo marinus } \\
\hline Number & Control & $1.0 \mathrm{nM}$ ANP & $10.0 \mathrm{nM}$ ANP & Post-ANP \\
\hline \multirow[b]{2}{*}{5} & $(n=13)$ & $(n=10)$ & $(n=12)$ & $(n=9)$ \\
\hline & $\begin{array}{l}5.19 \\
\pm 0.45\end{array}$ & $\begin{array}{l}5.16 \\
\pm 0.71\end{array}$ & $\begin{array}{c}6.81 \\
\pm 0.90\end{array}$ & $\begin{array}{c}5.72 \\
\pm 0.74\end{array}$ \\
\hline \multirow[b]{2}{*}{6} & $(n=15)$ & $(n=13)$ & $(n=14)$ & $(n=12)$ \\
\hline & $\begin{array}{c}6.21 \\
\pm 0.64 \\
\end{array}$ & $\begin{array}{c}6.47 \\
\pm 0.91\end{array}$ & $\begin{array}{c}6.18 \\
\pm 0.31\end{array}$ & $\begin{array}{c}7.20 \\
\pm 0.76\end{array}$ \\
\hline \multirow[t]{4}{*}{ Average: } & 5.74 & 5.90 & 6.47 & 6.57 \\
\hline & \pm 0.40 & \pm 0.60 & \pm 0.44 & \pm 0.55 \\
\hline & 6.37 & $=$ Average of a & control animals & \\
\hline & & & & \\
\hline
\end{tabular}

Rana catesbeiana

\begin{tabular}{ccccc}
\hline Number & Control & $1.0 \mathrm{nM}$ ANP & $10.0 \mathrm{nM}$ ANP & Post-A-NP \\
\hline \multirow{3}{*}{4} & N/A & 5.33 & $(n=10)$ & $(n=10)$ \\
& & \pm 2.91 & \pm .50 & 2.38 \\
& $(n=10)$ & $(n=12)$ & $(n=13)$ & $(n=12)$ \\
5 & 5.47 & 6.81 & 4.80 & 7.61 \\
& \pm 0.34 & \pm 0.76 & \pm 0.43 & \pm 1.01 \\
& $(n=9)$ & $(n=9)$ & $(n=13)$ & $(n=10)$ \\
6 & 5.31 & 5.32 & 5.31 & 5.33 \\
\multirow{4}{*}{ Average } & \pm 0.31 & \pm 0.22 & \pm 0.41 & \pm 0.73 \\
\cline { 2 - 5 } & 5.39 & 6.10 & 4.90 & 5.26 \\
& \pm 0.23 & \pm 0.46 & \pm 0.30 & 0.58 \\
& 5.07 & $=$ Average of all control animals & \\
& & & & \\
& & &
\end{tabular}




\section{DISCUSSION}

The data show that Bufo marinus and Rana catesbeiana have exceptionally high hydraulic conductivity on a mass specific basis (CFC) equal to $6.68 \pm 0.51$ and $5.07 \pm 0.23 \mathrm{ml} \cdot \mathrm{min}^{-1} \cdot \mathrm{kg}^{-1} \cdot \mathrm{mmHg}^{-1}$, respectively. These values are nearly an order of magnitude larger than those found in mammals using similar methods. There are no comparable data on vertebrates other than mammals, except for an abstract by Smits and Ilowite (1989) concerning the isolated hindlimbs of a toad. The value obtained by them $\left(1.59 \pm 0.09 \mathrm{ml} \cdot \mathrm{min}^{-1} \cdot \mathrm{kg}^{-1} \cdot \mathrm{mmHg}^{-1}\right)$, primarily representative of skeletal muscle, is much lower than the whole-body values obtained here. While that value is still higher than any comparable mammalian estimates, indicating the same trend as seen here, only an abstract is published and comparison of methods to this datum has not been attempted.

The Ringers used during perfusion had a protein concentration of only 0.1 grams per liter. This was done in order to alleviate any consequent build-up of protein in the interstitium which would artificially raise the filtration rate after filtration had occurred for a certain amount of time. Plasma protein concentrations in Bufo and Rana range from 3-5 grams per liter. The addition of Ringers to physiological levels would act opposite to the direction of filtration, acting to reabsorb fluid from the vasculature and render a lower rate of filtration for a given hydrostatic pressure. This factor would not change $\mathrm{CFC}$, as the rates of filtration at 
different pressures would be offset by equivalent colloid forces, and the differential between rates would be equal.

No significant effects of atrial natriuretic peptide were found during this preparation. It would appear that the hydraulic conductivity of capillaries as a whole within these species were not changed by ANP. This is very surprising considering the single vessel studies which document a pronounced increase in hydraulic conductivity in response to ANP in the mesenteric capillaries of frogs (Meyer and Huxley, 1990; Meyer et al., 1992) as well as an ability to suppress these reactions in volume loaded frogs (Meyer et al., 1992) as well as in many mammalian species (see Introduction). Multiple solutions of ANP were not used and from the paucity of data collected, it is difficult to state absolutely that ANP does not affect hydraulic conductivity.

This lack of effect by ANP may be explained by a surgical technique which included transient, but pronounced, occlusion of systemic arches during the exposure of the pulmocutaneous artery and cannulation of the systemic arches. This resulted in high atrial pressures as judged visually by obvious distension of the heart. Although the effects of ANP have not been documented in amphibians outside single vessel studies of the mesenteric capillaries of frog (Meyer and Huxley, 1990; Meyer et al., 1992), results observed in other vertebrates suggest that this distension would result in a release of ANP and consequent increase in CFC 
(see Introduction). A reversible effect was demonstrated in frog mesenteric capillaries (Meyer and Huxley, 1990; Meyer et al., 1992); thus, perfusion with ANP free Ringers solutions may have attenuated this response. However, complete washout of ANP at an organismal level may not be as straightforward as in a single capillary. Even if the ANP was washed out completely by Ringers, a refractory response to ANP over such a short time period has not been demonstrated to my knowledge, and thus we should be able to discern an increase in CFC with a reintroduction of ANP. This was not observed (see below). It is therefore possible that the CFC values obtained here are above normal physiological levels due to ANP stimulation. Assuming the average 2.2 fold increase in $\mathrm{HC}$ in response to ANP as found in the frog mesenteric capillaries by Meyer and Huxley (1990) is applied to the values of CFC obtained here, one would expect CFC in the toad and frog to be to 3.04 and $2.30 \mathrm{ml} \cdot \mathrm{min}^{-1} \cdot \mathrm{kg}^{-1} \cdot \mathrm{mmHg}^{-1}$, respectively.

Pre- and post-capillary resistances were calculated to be 1.81 and 0.32 $\mathrm{mmHg} \cdot \mathrm{min} \cdot \mathrm{ml}^{-1}$, as derived from the least-squares linear fit method. The estimated post- to pre-capillary resistance is thus 0.18 and was used to calculate all capillary pressures used for the estimates of CFC. The alternative method utilizing the differences between consecutive points only yielded a slightly higher estimate of post-capillary resistance $\left(0.37 \mathrm{mmHg} \cdot \mathrm{min} \cdot \mathrm{ml}^{-1}\right)$, consequently a higher resistance ratio $(0.20)$. The difference between the estimates is low, and would result in only a small change in estimated capillary pressure. For instance, a distinct change in the 
resistance ratio from $0.18 \pm 0.07$ with initial $P_{a}=20 \mathrm{mmHg}$ and $P_{v}=5 \mathrm{mmHg}$, followed by a decrease in $\mathrm{P}_{\mathrm{v}}$ to $3 \mathrm{mmHg}$ would only yield an effective capillary pressure difference of $0: 10 \mathrm{mmHg}$ using the two different resistance ratios. CFC of the range measured (using a $\mathrm{CFC}=6 \mathrm{ml} \cdot \mathrm{min}^{-1} \cdot \mathrm{kg}^{-1} \cdot \mathrm{mmHg}^{-1}$ ) would then only yield a $0.29 \mathrm{ml} \cdot \mathrm{min}^{-1} \cdot \mathrm{kg}^{-1} \cdot \mathrm{mmHg}^{-1}$ difference in the calculated CFC. The absolute difference in capillary pressure would be closer to $0.7 \mathrm{mmHg}$.

These derived resistances should sum to yield the total systemic resistance, as they are in series. The derived resistances underestimated the systemic resistance by an average of $25 \%$ for both methods. Thus, the resistance ratio is the more pertinent value and the derived absolute pre- and post-capillary resistances are subject to error.

Isovolumetric capillary pressure, the pressure of the capillary where no net filtration occurs, was estimated by two separate methods. The Pappenheimer and Soto-Rivera (1948) method (method A) utilizes the values for isovolumetric venous pressures at different flows and extrapolates those back to zero flow, such that all pressures in the system are equal and $\mathrm{P}_{\mathrm{ci}}=\mathrm{P}_{\mathrm{vi}}=\mathrm{P}_{\mathrm{ai}}$ (see Methods). The isovolumetric capillary method obtained on Bufo marinus using this method during Ringers perfusion was $7.2 \pm 1.6 \mathrm{mmHg}$. A slightly higher value, $7.8 \pm 0.5 \mathrm{mmHg}$, was obtained as the mean of individual lines plotted between consecutive measurements. 
This value is intuitively troubling. One expects that when no filtration is taking place, the capillary pressure is equal and opposite to COP according to the Starling equation (Equation 1, Introduction). If the COP is lowered by $1 \mathrm{mmHg}$, then the isogravimetric hydrostatic pressure should also be lowered by 1 when no filtration takes place. This would continue until at zero COP (essentially the COP used here) the isovolumetric capillary pressure would also be zero. One might be tempted to estimate isovolumetric capillary pressure using the estimate obtained by extrapolating the isovolumetric arterial pressures to zero, $1.3 \pm 2.3 \mathrm{mmHg}$. This value was not significantly different from zero according to the linear regression, a much more intuitively satisfying number. However, several problems arise from using this estimate. First, the slope of the arterial line is greater, and thus the extrapolation is more sensitive to proportional error. Second, the flow rate of the perfusion pump drives the hydrostatic pressure. Although the arterial pressure would change according to the resistance of the system, the venous pressure utilized to achieve isovolumetry is more reflective of the state of the system. Third, the venous pressure more closely approximates the capillary pressure and is thus a better estimator of it.

The best validation of using the value derived from the venous line however, lies in the alternate estimate of isovolumetric capillary pressure (method B). This method used the calculated capillary pressures at different filtration rates and extrapolated them back to zero filtration. For Bufo marinus this method yielded 
an isovolumetric capillary pressure of $7.4 \pm 0.2 \mathrm{mmHg}$, a value midway between the other estimates of $\mathrm{P}_{\mathrm{ci}}$. This method is not completely independent of the other. Resistance ratios calculated from the previous method are used to derive the capillary pressure for each independent measurement. However, as discussed above an increase of the ratio from 0.18 to 0.25 would change capillary pressure only by $0.7 \mathrm{mmHg}$ and the effect on the slope is small. Thus, the effect of error on the resistance ratio would shift the intercept only slightly, upwards to $1 \mathrm{mmHg}$.

The isovolumetric capillary pressure for the frog as obtained from method B was $6.3 \pm 0.7 \mathrm{mmHg}$, lower than that found for the toad. Data were not collected isovolumetrically for the frog. This required using the estimate of post- and precapillary pressure obtained from the toad to calculate capillary pressure. As explained above, this should not change isovolumetric capillary pressure dramatically. There was a wider range of $\mathrm{P}_{\mathrm{ci}}$ in the frog where the individual best fit lines had similar slopes $\left(\mathrm{CFC}_{b}\right)$ but different intercepts $\left(\mathrm{P}_{\mathrm{ci}}\right)$. The wider range of $\mathrm{P}_{\mathrm{ci}}$ in the frog does not seem to correlate to any of the relevant variables. Although it appears to correlate positively with the measured CFC (either method) in frogs, there is a negative correlation in toads for the same comparison. This variation in $\mathrm{P}_{\mathrm{ci}}$ further necessitates the need for an independent study of pre- to post-capillary resistances in Rana but does not necessarily invalidate the measurement of CFC due to the small effect a change in the resistance ratio will have. 
Under in vivo conditions, with normal protein content, one would expect the value obtained here for isovolumetric capillary pressure, using a protein content of $0.1 \%$, to be increased by an amount equal to COP, such that the isovolumetric pressure would be able to withstand the reabsorptive forces and remain at isovolumetry. Thus, for Bufo marinus using a middle estimate of $7.5 \mathrm{mmHg}$ as isovolumetric capillary pressure and a $\mathrm{COP}$ of approximately $4 \mathrm{mmHg}$ (Hillman $e t$ al., 1987), the in vivo isovolumetric capillary pressure would be approximately 11.5 mmHg.

For Rana catesbeiana, using an average $\mathrm{P}_{\mathrm{ci}}$ of $6.3 \mathrm{mmHg}$ and a COP of 3 $\mathrm{mmHg}$, an approximate value from the literature (Churchill et al., 1927; Baldwin et al., 1993; Pinder and Smits, 1993; Hillman et al., 1987), the in vivo isovolumetric capillary pressure would be approximately $9.3 \mathrm{mmHg}$.

It is interesting to note that the value obtained for isovolumetric capillary pressure using Method A as developed by Pappenheimer and Soto-Rivera (1948), after correcting for colloids, yields a value strikingly similar to the mean circulatory filling pressure as measured recently (Todd Hoagland, unpublished data). The intent of the isovolumetric method is to extrapolate isovolumetric data back to zero flow such that $P_{a}=P_{c}=P_{v}$. These are the exact conditions which define MCFP (Rothe, 1993).

An estimate for in vivo capillary pressure for these species is now possible using the resistance ratio obtained here. For Bufo marinus in vivo, at rest venous 
pressures have been measured at $8.5 \mathrm{mmHg}$ (Hillman et al., 1987) and $8.6 \mathrm{mmHg}$ (Todd Hoagland, unpublished data). Average in vivo, at rest arterial pressures have been measured at $23.7 \mathrm{mmHg}$ (West and Smits, 1994) and $23.6 \mathrm{mmHg}$ (Withers et al., 1988). Using any combination of the above estimates and the resistance ratio of 0.18 , an in vivo estimated capillary pressure of $10.8 \mathrm{mmHg}$ is predicted.

For Rana catesbeiana, using an in vivo, at rest venous pressure of 9.5 or 8.0 $\mathrm{mmHg}$ (Hillman et al., 1987) and an in vivo, at rest arterial pressure of $25.6 \mathrm{mmHg}$ (Todd Hoagland, unpublished data), the estimated in vivo capillary pressure is between $10.7-12.0 \mathrm{mmHg}$.

West and Smits (1994) measured flows and arterial pressures in Bufo marinus and estimated resistance but used a venous pressure of $5 \mathrm{mmHg}$, a value much lower than those in the literature. If a $\mathrm{P}_{\mathrm{v}}$ of $8.5 \mathrm{mmHg}$ is used with their other data, their values for aortic and carotid resistance would be 0.72 and 12.7 $\mathrm{mmHg} \cdot \mathrm{min} \cdot \mathrm{ml}^{-1} \cdot \mathrm{kg}^{-1}$, respectively. Since these systems are in parallel, summing their reciprocals would yield a total systemic resistance of 0.68 $\mathrm{mmHg} \cdot \mathrm{min} \cdot \mathrm{ml}^{-1} \cdot \mathrm{kg}^{-1}$. The value obtained here in Bufo yielded a systemic resistance of $0.44 \mathrm{mmHg} \cdot \mathrm{min} \cdot \mathrm{ml}^{-1} \cdot \mathrm{kg}^{-1}$. This preparation showed a lower resistance, although the data from West and Smits (1994) indicated a high variation between animals. This indicates the possibility that fewer capillary beds were open or the system was operating on a different pre- to post-capillary resistance or a combination of the two. The lower resistance also demonstrates that the cannulation 
technique used to obtain venous outflow did not greatly affect flow out of the system, as venous pressures were monitored within the outflow cannula, and not within the circulation itself.

Single vessel measurements of HC in amphibian mesenteric capillaries are not dramatically different from mammalian values (Michel, 1984), whereas the CFC values presented here are dramatically higher than mammalian values using similar methods. However, considering the variety of unknkowns such as capillary diameter, capillary density and capillary length makes the extrapolation to mass specific, much less whole body values, difficult at best. Further, it is indeed likely that mesenteric capillaries are not representative of the body as a whole. Baldwin et al. (1993), found a variability in the permeability to protein in frogs. This is in disagreement with Curry et al. (1976) who found no correlation in frog mesenteric capillaries between molecular size and the reflection coefficient of each.

It is troubling that no effect of histamine for cerebral venules has been found (Crone, 1986) or for single mesenteric capillaries (Curry, 1986). These data indicate a response to histamine in a limited sample size $(n=1)$. However, the effects of histamine are not consistent within all tissues, such as the pulmonary system where avoidance of edema is critical (Guyton and Hall, 1996). Cerebral edema is dangerous as well, and a lack of response to histamine within the brain would not be surprising. The mesenteric response to histamine in other species is undocumented to my knowledge. 
Multiple factors were used to assess that the animal was being perfused properly and the preparation was viable. Post-mortem dissection of several specimens indicated a sufficient perfusion of all tissues, as judged by the lake of erythrocytes and a pale color. Evans Blue perfused through the system at the end of a treatment also showed up in all tissues inspected. Although in the cranial cavity it was not entirely apparent.

The lack of obvious coloration in the cranial cavity when perfused by Evans blue could possibly be attributable to a lack of flow in the carotid arteries. Due to the tripartite nature of the systemic arches consisting of already distinct pulmocutaneous, systemic and carotid arteries, the cannulation may have exclusively perfused the systemic portion. Edema was often seen around the eyes and in the tongue however, which are also perfused by the carotid artery, thus indicating that it was indeed perfused sufficiently. Separation of the carotid and systemic arteries seem to be incomplete within the systemic arches and lack of color in the cranial cavity may simply be indicative of an inability of Evans Blue to cross the cerebral capillary walls. If it was not perfused, or perfused at a lower rate, the estimated filtration rates would be an underestimate on a mass specific basis which would underestimate the CFC. The flow of the carotid artery accounts for a relatively small proportion of $\mathrm{Q}_{\text {sys }}, 3.3$ versus $30.1 \mathrm{ml} \cdot \mathrm{min}^{-1} \cdot \mathrm{kg}^{-1}$, respectively (West and Smits, 1994). 
Early experiments not included in this data set showed that perfusion with Ringers without the anaesthetic benzocaine resulted in a "reawakening" of an animal during the in vitro preparation. These animals were quickly put back down with a bolus perfusion of MS-222 (Methanesulfonate Salt), and subsequent perfusions all took place with benzocaine.

Oxygen delivery to the system was enhanced by continuous bubbling of the perfusate with pure oxygen. As hypoxia has been shown to effect the hydraulic conductivity of individual capillaries (Oleson and Crone, 1986), lack of sufficient oxygen delivery was a concern. Continuous pulsation of atrial tissues during the preparation indicated viability of that specific tissue. Oxygen delivery exceeded basal metabolic rates (see Methods). As CFC did not change significantly over time (see results), it was assumed that the system was viable and not hypoxic.

Arterial and venous pressures were normally kept at a relation such that a positive filtration rate was seen throughout most of these preparations. This would result in edemic tissue in the absence of lymphatic uptake from the interstitium, thus potentially increasing the interstitial pressure which would naturally alter the balance of filtration forces. In part, this was why the preparations were used for only a limited number of traces. The dismissal of this potential flaw in experimental method is justified by three facts. First, significant change in CFC was not seen over time (see Results). Second, the method of CFCa utilizes the difference between consecutive measurements, where presumably the interstitial pressure 
differences would be negligible. Third, the compliance of the interstitium is immense. As measured by Mike Georgitsis (unpublished data), the compliance of the lymphatic sacs are on the order of $200-500 \mathrm{ml} \cdot \mathrm{mmHg}^{-1} \cdot \mathrm{kg}^{-1}$.

\section{Conclusion}

The interspecific difference of CFC seen in toads and frogs, $6.68 \pm 0.51$ and $5.07 \pm 0.23 \mathrm{ml} \cdot \mathrm{min}^{-1} \cdot \mathrm{kg}^{-1} \cdot \mathrm{mmHg}^{-1}$, respectively is highly suggestive of a direct relationship to total capillary surface area. Blood volume is higher in toads than frogs on a mass specific basis, 7.4 and $5.3 \%$ of total body weight, respectively (Thorson, 1964). This is primarily due to the higher aerobic capacity of the toad (Hillman, 1987), resulting in a higher blood volume per unit mass. Since CFC is essentially a combined term for the product of $\mathrm{HC}$ and surface area, $\mathrm{HC}=\mathrm{CFC} / \mathrm{S}$. Roughly, looking at the ratio of CFC to blood volume, with the assumption that capillary surface area is proportional to blood volume, Bufo has a ratio of 0.90 versus a ratio of 0.95 for Rana. Thus, Bufo has a slightly lower relative HC than does Rana.

The in vivo isovolumetric capillary pressure for toads was calculated (see above) to be approximately $11.5 \mathrm{mmHg}$ and the resting capillary pressure was calculated to be $10.8 \mathrm{mmHg}$. The in vivo isovolumetric capillary pressure for frogs was calculated to be approximately $9.3 \mathrm{mmHg}$ and the resting capillary pressure was calculated to be $10.7-12.0 \mathrm{mmHg}$. 
Despite an incredibly high CFC, which implies high rates of filtration, these data indicate that in vivo, isovolumetric capillary pressure is similar to the resting capillary pressure. Assuming vasomotor control over capillary pressure, capillary pressures might be maintained at a level where the estimated rates of filtration can be sufficiently matched by lymphatic return.

The interspecific difference in isovolumetric capillary pressure may be the most interesting result of all. During dehydration or hemorrhage after loss of vasomotor control over capillary pressure, the capillary pressure will presumably drop. The higher isovolumetric capillary pressure of toads implies that the outward filtration in toads will be reversed to favor reabsorptive forces sooner than it will in frogs. This is consistent with the superior dehydration tolerance of toads versus frogs. 


\section{LITERATURE CITED}

Almeida, F:A., M. Suzuki and T. Maack. 1986. Atrial natriuretic factor increases hematocrit and decreases plasma volume in nephrectomized rats. Life Sci. 39:1193-1199.

Aranjaniyil, K.P., B.M. Ravi, K.J. Rama an K.S. Rameshwar. 1987. Coexistence of guanylate cyclase and atrial natriuretic factor receptor in a $180-\mathrm{kD}$ protein.

Science. 235:1224-1226.

Arendt, R.M., A.L. Gerbes, D. Ritter, E. Stangl, P. Bach and J. Zahringer. 1986. Atrial natriuretic factor in plasma of patients with arterial hypertension, heart failure or cirrhosis of the liver. J. Hypertension 4, Suppl. 2:S131-S135.

Aukland, K. and H.O. Fadnes. 1973. Protein concentration of interstitial fluid collected from rat skin by a wick method. Acta Physiol. Scand. 57:180-192.

Baeyens, D.A., E. Price, C.J. Winters and D.L. Vesely. 1989. Diving increases atrial natriuretic factor-like peptide in freshwater diving turtles. Comp. Biochem. Physiol. 94A:515-518.

Baldwin, A.L., P. Ferrer, J.S. Rozum, and R.W. Gore. 1993. Regulation of water balance between blood and lymph in the frog, Rana pipiens. Lymphology. $26: 4-18$

Baustian, M., 1988: The contribution of lymphatic pathways during recovery from hemorrhage in the toad, Bufo marinus. Physiol. Zool. 61: 555-563. 
Biollaz, J.J., J. Nussberger, B. Waeber and H.R. Brunner. 1986. Clinical pharmacology of atrial natriuretic (3-28) eicosahexapeptide. J. Hypertension 4, Suppl. 2:S101-108.

Bjerkhoel, P. and J. Lundvall. 1995. Pronounced plasma fluid loss into dependent regions on standing. Acta Physiol. Scand. 154:275-276.

Brace, R.A. and P.S. Gold. 1984. Fetal whole-body interstitial compliance, vascular compliance, and capillary filtration coefficient. Am. J. Physiol. 247:R800-R805.

Burggren, W.W. 1982. Pulmonary blood plasma filtration in reptiles: A wet vertebrate lung? Science. 215:77-78.

Clough, G. 1988. A comparison of the effects of human atrial natriuretic peptide (ANP) and a synthetic atriopeptin III (APIII) upon capillary permeability (Abstract). Int. J. Microcirc. Clin. exp. 7:S45.

Conklin, R.E. 1930. The formation and circulation of lymph in the frog I. The rate of lymph production. Am. J. Physiol. 95:91-97.

Cousins, K.L. and A.P. Farrell. 1996. Stretch-induced release of atrial natriuretic factor from the heart of rainbow trout (Oncorhyncus mykiss). Can. J. Zool. $74: 380-387$

Crone, C. 1965. Facilitated transport of glucose from blood into brain. J. Physiol. (London). 181:103-113. 
Crone, C. 1986. Modulation of solute permeability in microvascular endothelium. Federation Proc. 45:77-83.

Crone, C. and O. Christensen. 1981.. Electrical resistance of a capillary endothelium. J. Gen. Physiol. 77:349-371.

Crone, C. and D.G. Levitt. 1984. The exchange of small solutes through the capillary wall. Handbook of Physiology, sect. 2, The Cardiovascular System, vol IV, The Microcirculation. (eds. Renkin, E.M., Michel, C.C.). American Physiological Society, 1984. pp. 411-466.

Curry, F.E. 1979. The effect of temperature on the hydraulic conductivity of single capillaries of frog mesentery: The role of albumin in the perfusate. Microvasc. Res. 17:Pt 2, S82, (Abstr.)

Curry, F.E. 1986. Determinants of capillary permeability: A review based on single capillary studies in the frog. Circ. Res. 59:367-380.

Curry, F.E., J.C. Mason and C.C. Michel. 1976. Osmotic reflexion coefficients of capillary walls to low molecular weight hydrophilic solutes measured in single perfused capillaries of the frog mesentery. J. Physiol. London. $261: 319-336$

DeBold, A.J., H.B. Borenstein, A.T. Veress and H. Sonnenberg. 1981. A rapid and potent natriuretic response to intravenous injection of atria myocardial extracts in rats. Life Sci. 28:89-94. 
De Mello, W.C. 1984. Modulation of junctional permeability. Federation Proc. 43:2692-2696.

Dejours,P. 1975. Principles of Comparative Respiratory Physiology. American Elsevier Publishing Co., Inc., New York.

Diana, J.N. and R.S. Kaiser. 1970. Pre- and postcapillary resistance during histamine infusion in the isolated dog hindlimb. Amer. J. Physiol. 218:132-142.

Djojusugito, A.M., B. Folkow and A.G.B. Kovach. 1968. The mechanisms behind the rapid blood volume restoration after hemorrhage in birds. Acta Physiol. Scand. 74:114-122.

Eliassen, E., B. Folkow, S.M. Hilton, B. Obert and B. Rippe. 1974. Pressure-volume characteristics of the interstitial fluid space in the skeletal muscle of the cat. Acta Physiol. Scand. 90:583-593.

Epstein, M., R.D. Loutzenhiser, E. Friedland, R.M. Aceto, M.J.F. Camargo and S.A. Atlas. 1986. Increases in circulating atrial natriuretic factor during immersion-induced central hypervolemia in normal humans. J. Hypertension 4, Suppl. 2:S93-S99.

Fluckiger, J.P., B. Waeber, G. Matsueda, B. Delaloye, J. Nussberger and H.R. Brunner. 1986. Effect of atriopeptin III on hematocrit and volemia of nephrectomized rats. Am. J. Physiol. 251:H880-H883. 
Fraser, P.A., L.H. Smaje and A. Verrinder. 1978. Microvascular pressures and filtration coefficients in the cat mesentery. J. Physiol. (Lond.). 283:439-456.

Garlick, D.G. and E.M. Renkin. 1970. Transport of large molecules from plasma to interstitial fluid and lymph in dogs. Am. J. Physiol. 219:1595-1605.

Gilles, J., P. Netchitailo, F. Leboulenger, M. Cantin, G. Pelletier and H. Vaudry. 1990. Localization and characterization of the $\mathrm{N}$-terminal fragment of atrial natriuretic factor (ANF) precursor in the frog heart. Peptides. 11:199-204.

Glass, M.L., L.G.S. Branco, J. Antunes-Rodrigues and J. Gutkowska. 1996.

Characterization of the atrial natriuretic factor system in lungs of the toad Bufo paracnemis. J. Exp. Biol. 199:1493-1499

Goetz, K.L. 1988. Physiology and pathophysiology of atrial peptides. Am. J. Physiol. 254:E1-15.

Gore, R.W. and P.F. McDonagh. 1980. Fluid exchange across single capillaries. Ann Rev. Physiol. 42:337-357.

Grega, G.J. 1986. Role of the endothelial cell in the regulation of microvascular permeability to molecules. Federation Proc. 45:75-76.

Grega, G.J., J.J. Maciejko, R.M. Raymond and D.P. Sak. 1980. The interrelationship among histamine, various vasoactive substances, and macromolecular permeability in the canine forelimb. Circ. Res. 46: 264-275. 
Grega, G.J., R.L. Kline, D.E. Dobbins and F.J. Haddy. 1972. Mechanisms of edema formation by histamine administered locally into canine forelimbs. Am. J. Physiol. 223:1165-1171.

Grega, G.J., S.W. Adamski and D.E. Dobbins. 1986. Physiological and pharmacological evidence for the regulation of permeability. Federation Proc. 45:96-100.

Gutkowska, J. and M. Nemer. 1989. Structure, expression and function of atrial natriuretic factor in extraatrial tissues. Endocr. Rev. 10:519-536

Guyton, A.C. 1963. A concept of negative interstitial pressure based on pressures in implanted perforated capsules. C.irc. Res. 12:399-414.

Guyton, A.C. and J.E. Hall. 1996. Textbook of Medical Physiology, 9th ed. W.B. Saunders Co., Philadelphia, PA.

Guyton, A.C., D. Polizo and G.G. Armstrong. 1954. Mean circulatory filling pressure measured immediately after cessation of cardiac pumping. Am. J. Physiol. 179:261-267.

Hargens, A.R., R.W. Millard and K. Johansen. 1974. High capillary permeability in fishes. Comp. Biochem. Physiol. 48A:675-680.

Hargens, A.R., R.W. Millard, K. Pettersson and K. Johansen. 1987. Gravitational haemodynamics and oedema prevention in the giraffe. Nature. 329:59-60.

Heltianu, C., M. Simionescu and N. Simionescu. 1982. Histamine receptors of the microvascular endothelium revealed in situ with a histamine-ferretin 
conjugate: Characteristic high-affinity binding sites in venules. J. Cell. Biol. 93:357-364.

Hillman; J: 1981. Further studies on beta-adrenergic control of transcapillary fluid absorption from skeletal muscle to blood during hemorrhage. Acta Physiol. Scand. 112:281-286.

Hillman, J. and J. Lundvall. 1981. Classification of beta-adrenoceptors in the microcirculation of skeletal muscle. Acta Physiol Scand. 113:67-71.

Hillman, S.S. 1987. Dehydrational effects on cardiovascular and metabolic capacity in two amphibians. Physiol. Zool. 69:608-613.

Hillman, S.S. 1991. Cardiac scope in amphibians: Transition to terrestrial life. Can. J. Zool. 69:2010-2013.

Hillman, S.S. and P.C. Withers. 1988. The hemodynamic consequences of hemorrhage and hypernatremia in two amphibians. J. Comp. Physiol. B. $157: 807-812$.

Hillman, S.S. and R.W. Sommerfeldt. 1981. Microsphere studies of amphibian systemic blood flow redistribution during dehydration, hypovolemia, and salt load. J. Exp. Zool. 218:305-308

Hillman, S.S., 1980. Physiological correlates of differential dehydration tolerance in anuran amphibians. Copeia, 1:125-129

Hillman, S.S., A. Zygmunt and M. Baustian. 1987. Transcapillary fluid forces during dehydration in two amphibians. Physiol. Zool. 60:339-345. 
Huxley, V.H. and D.J. Meyer Jr. 1990. Capillary permeability: An albumin component attenuates active changes in Lp. Am. J. Physiol. 259:H1357-1364.

Huxley, V.H. and F.E. Curry. 1995. Dynamics of microvessel permeability using single frog (Rana pipiens) mesenteric capillaries. Physiol. Zool. 68:58 (Abstract A8).

Imamura, T., N. Ohnuma, F. Iwasa, M. Furaya, T. Hayashi, T. Ishihara and T. Noguchi. 1988. Protective effect of a human atrial natriuretic polypeptide (alpha-hANF) on chemical-induced pulmonary edema. Life Sci. 42:403-414.

Jacobsson, S. and I. Kjellmer. 1964. Flow and protein content of lymph in resting and exercising smooth muscle. Acta Physiol. Scand. 60:278-285.

Johansen, K. and D. Hanson. 1968. Functional anatomy of the hearts of lungfishes and amphibians. Am. Zool. 8:191-210.

Jones, J.M., L.A. Wentzell and D.P. Toews. 1992. Posterior lymph heart pressure and rate and lymph flow in the toad Bufo marinus in response to hydrated and dehydrated conditions. J. Exp. Biol. 169:207-220.

Jones, J.M., A.K. Gamperl, A.P. Farrell and D.P. Toews. 1997. Direct measurement of flow from the posterior lymph hearts of hydrated and dehydrated toads (Bufo marinus). J. Exp. Biol. 200:1695-1702. 
Laine, G.A. and H.J. Granger. 1985. Microvascular, interstitial and lymphatic interactions in normal heart. Am. J. Physiol. 249:H834-H842.

Laine, G.A. and S.J. Allen. 1991. Left ventricular myocardial edema: Lymph flow, interstitial fibrosis, and cardiac function. Circ. Res. 68:1713-1721.

Landis, E.M. 1925. The capillary pressure in frog mesentery as determined by micro-injection methods. Am. J. Physiol. 548:548-570.

Lang, R.E., H. Tholken, D. Ganten, F.C. Luft, H. Ruskoaho and T. Unger. 1989. Atrial natriuretic factor - a circulating hormone stimulated by volume loading. Nature (London) 314:264-266.

Lee, R.W. and S. Goldman. 1989. Mechanism for decrease in cardiac output with atrial natriuretic peptide in dogs. Am. J. Physiol. 256:H760-765.

Lillywhite, H.B. 1985. Postural edema and blood pooling in snakes. Physiol. Zool. $58: 759-766$.

Lillywhite, H.B. 1993a. Orthostatic intolerance of viperid snakes. Physiol. Zool. 66:1000-1014.

Lillywhite, H.B. 1993b. Subcutaneous compliance and gravitational adaption in snakes. J. Exp. Zool. 267:557-562.

Lillywhite, H.B. and A.W. Smits. 1984. Lability of blood volume in snakes and its relationship to activity and hypertension. J. Exp. Biol. 152:59-65.

Lillywhite, H.B. and F.H. Pough. 1983. Control of arterial pressure in aquatic sea snakes. Am. J. Physiol. 244:R66-R73. 
Lillywhite, H.B. and L.H. Smith. 1981. Haemodynamic responses to haemorrhage in the snake, Elaphe obsoleta obsoleta. J. Exp. Biol. 94:275-283

Einde, B., G. Chisholm and S. Rosell. 1974. The influence of sympathetic activity and histamine on the blood-tissue exchange of solutes in canine adipose tissue. Acta Physiol. Scand. 92:145-155.

Lundvall, J. and J. Hillman. 1978. Fluid transfer from skeletal muscle to blood during hemorrhage. Importance of beta-adrenergic vascular mechanisms. Acta Physiol. Scand. 102:450-458.

Lundvall, P., S. Bjerkhoel, S. Quittenbaum and P. Lindgren. 1996. Rapid plasma volume decline upon quiet standing reflects large filtration capacity in dependent limbs. Acta Physiol. Scand. 1996. 158:161-167.

Majno, G., S.M. Shea and M. Levelthal. 1969. Endothelial contraction induced by histamine-type mediators: An electron microscopic study. J. Cell Biol. 42:647-672.

Marciniak, D.L., D.E. Dobbins, J.J. Maciejko, J.B. Scott, F.J. Haddy and G.J. Grega. 1978. Antagonism of histamine edema formation by catecholamines. Am. J. Physiol. 234(2):H180-H185

Mason, J.C., F.E. Curry and C.C. Michel. 1977. The effects of proteins upon the filtration coefficient of individually perfused frog mesenteric capillaries. Microvasc. Res. 13:185-202. 
McDonagh, P.F. and R.W. Gore. 1978. Comparison of hydraulic conductivities in single capillaries of red versus white skeletal muscle. Microvasc. Res. 15:269 (Abstr. \#23).

Meyer, D.J. Jr. and V.H. Huxley. 1990. Differential sensitivity of exchange vessel hydraulic conductivity to atrial natriuretic peptide. Am. J. Physiol. 258:H521-H528

Meyer, D.J. Jr., V.H. Huxley and M.K. McKay. 1992. Volume status influences atrial peptide-induced water conductivity changes in leopard frog mesenteric capillaries. J. Physiol. 447:33-47.

Michel, C.C. 1984. Fluid movements through capillary walls. In: Handbook of Physiology. The Cardiovascular System. The Microcirculation. sec. 2, vol. IV, chap. 9, p. 375-409. Bethesda, MD: Am. Physiol. Soc.

Middler, S.A., C.R. Kleeman and E. Edwards. 1968. Lymph mobilization following acute blood loss in the toad, Bufo marinus. Comp. Biochem. Physiol. $24: 343-353$

Miller, F.N. and D.E. Sims. 1986. Contractile elements in the regulation of macromolecular permeability. Federation Proc. 45:84-88.

Morimoto, T., K. Miki, H. Nose, Y. Tanaka and S. Yamada. 1981. Transvascular fluid shift after blood volume modification in relation to compliance of the total vascular bed and interstitial fluid space. Jap. J. Physiol. 31:869-878. 
Morris, J. L. 1981. Structure and function of ciliated peritoneal funnels in the toad kidney (Bufo marinus). Cell and Tissue Res. 217:599-610.

Murad, M.F., W.P. Arnold, C.K. Mittal and J.M. Braughler. 1979. Properties and regulation of guanylate cyclase and some proposed functions for cyclic GMP. In: Advances in Cyclic Nucleotide Research, vol 11, ed. Greengard, P. and Robinson, G.A., pp. 175-204. Raven Press, New York.

Netchitailo, P., L.M. Feuilloley, G. Pelletier, M. Cantin, A. DeLean, F. Leboulenger and $\mathrm{H}$. Vaudry. 1987. Identification of atrial natriuretic factor-like immunoreactivity in the frog heart. In: Biologically Active Atrial Peptides, vol. 1, American Society of Hypertension Symposium Series (ed. B.M. Brenner and J.H. Laragh), pp. 166-169. New York: Raven Press.

Oleson, S.-P. and C. Crone. 1984. Serotonin increases microvascular permeability in the brain. Int. J. Microcirc. Clin. Exp. 3:466.

Pappenheimer, J.R. and A. Soto-Rivera. 1948. Effective osmotic pressure of the plasma proteins and other quantities associated with the capillary circulation in the hindlimbs of cats and dogs. Am. J. Physiol. 152:471-491.

Pinder, A.W. and A.W. Smits. 1993. Mechanisms of acute hemoconcentration in bullfrogs in response to hypoxemia. Am. J. Physiol., 264(33):R687-R695 Prather, J.W., D.N. Bowes, D.A. Warrel and B.W. Zweifach. 1971. Comparison of capsule and wick techniques for measurement of interstitial fluid pressure. J. Appl. Physiol. 31:942-945. 
Renkin, E.M. and V.L. Tucker. 1996. Atrial natriuretic peptide as a regulator of transvascular fluid balance. News in Physiol. Sci. 11:138-143

Rippe, B. and G.J. Grega. 1978. Effects of isoprenaline and cooling on histamine induced changes of capillary permeability in the rat hindquarter vascular bed. Acta Physiol. Scand. 103:252-262

Rothe, C.F. 1993. Mean circulatory filling pressure: Its meaning and measurement. J. Appl. Physiol. 74:499-509

Ryan, U.S. 1986. The endothelial surface and responses to injury. Federation Proc. 45:101-108.

Samar, R.E., Coleman, T.G., 1978: Measurement of mean circulatory filling pressure and vascular capacitance in the rat. Am. J. Physiol. 234:H94-H100.

Sarelius, I.H. and V.H. Huxley. 1990. A direct effect of atrial peptide on arterioles of the terminal microvasculature. Am. J. Physiol. 258:R1224-1229.

Shoemaker, V.H. and K.A. Nagy. 1977. Osmoregulation in amphibians and reptiles. Ann. Rev. Physiol. 39:449-471.

Smits, A.W. and H.B. Lillywhite. 1985. Maintenance of blood volume in snakes: Transcapillary shifts of extravascular fluids during acute hemorrhage. J. Comp. Physiol. B, 155:305-310.

Smits, A.W. and R. Ilowite. 1989. Transcapillary fluid exchange in isolated toad hindlimbs. FASEB J. 3:A559. 
Spotila, J.R. and E.N. Berman. 1976. Determination of skin resistance and the role of the skin in controlling water loss in amphibians and reptiles. Comp. Biochem. Physiol. 55A:407-411.

Starling, E.H. 1896. On the absorption of fluids from connective tissue spaces. J. Physiol. (London). 19:312-326.

Stewart, R.H., D.A. Rohn, U. Mehlhorn, K.L. Davis, S.J. Allen and G.A. Laine. 1996. Regulation of microvascular filtration in the myocardium by interstitial fluid pressure. Am. J. Physiol. 271:R1465-R1469.

Sugimoto, E., K. Shigemi, T. Okuno, T. Yawata and T. Morimoto. 1989. Effect of ANP on circulating blood volume. Am. J. Physiol. 257:R127-131.

Tanaka, Y. 1979. Whole body transvascular filtration coefficient and interstitial space capacitance. Jap. J. Physiol. 29:181-193.

Taylor, A.E. and D.N. Granger. 1984. Exchange of macromolecules across the microcirculation. In: Handbook of Physiology. The Cardiovascular system. Microcirculation. Bethesda, MD: Am. Physiol. Soc., sect. 2, vol. IV, pt. 1, chapt. 11, pp. 467-520.

Thorson, T.B. 1964. The partitioning of body water in Amphibia. Physiol. Zool. 37:395-399.

Trippodo, N.C. and R.W. Barbee. 1987. Atrial natriuretic factor decreases whole-body capillary adsorption in rats. Am. J. Physiol. 257:R127-131. 
Tucker, V.L., K.E. Simanonok and E.M. Renkin. 1992. Tissue-specific effects of physiological ANP infusion on blood-tissue albumin transport. Am. J. Physiol. 263:R945-R953.

Tucker, V.L., T.L. Myers and C.J. Weber. 1995. Regulation of microvascular exchange by the ANP clearance receptor (Abstract). Microcirculation 2:88.

Vesely, D.L. and A.T. Giordano. 1992. Atrial natriuretic factor-like peptide and its prohormone within single cell organisms. Peptides. 13:177-182.

Ware, J., K.-A. Norbert and G. Nylander. 1980. Osmolar developments and altered thoracic duct lymph flow in hypovolaemic shock. Eur. Surg. Res. [Suppl. 1] $12: 48$

West, N.H. and A.W. Smits. 1994. Cardiac output in conscious toads (Bufo marinus). J. Exp. Biol. 186:315-323.

Wiederhielm, C.A. 1966. Transcapillary and interstitial transport phenomena in the mesentery. Federation Proc. 25:1789-1798.

Withers, P.C., S.S. Hillman, L.A. Simmons and A.C. Zygmunt. 1988.

Cardiovascular adjustments to enforced activity in the anuran amphibian, Bufo marinus. Comp. Biochem. Physiol. 89A:45-49.

Zatsman, M.L. and G.V. Thornhill. 1989. Plasma levels of atrial natriuretic factor in nonhibernating and hibernating marmots. Cronobiology. 26:196-198. 
Zhang, Y., E. Jenkinson and K.R. Olson. 1995. Vascular compliance and mean circulatory filling pressure in trout: Effects of ACE inhibition. Am. J. Physiol. 268:H1814-H1820.

Zweifach, B.W. and M. Integlietta. 1971. Measurement of blood plasma colloid osmotic pressure. II. Comparative study of different species. Microvasc. Res. 3:83-88. 